\title{
Self-rappelling Robot System for Inspection And Reconnaissance in Search and Rescue Applications
}

\author{
HAGEN SCHEMPF \\ Automatika, Inc. \\ 137 Delta Drive \\ Pittsburgh, PA 15238, USA \\ hschempf@foster-miller.com
}

\begin{abstract}
A new type of self-rappelling search-and-rescue robot with chassis articulation, dubbed SPIDAR, has been developed and tested for use by first-responders. SPIDAR is built around a set of articulating body-sections, running a modular running-gear configuration (wheels, legs, tracks, etc.) to allow for maximum terrainability in chaotic collapsed urban structures. The on-board tether-system allows for continuous powering and real-time data/video feedback. The tether serves as a tensile member that allows for rappelling and winching the robot into and out of precipices and crevasses, with a range of up to 30 meters. The system is deployable and operable by a single person off a remote console. This paper describes the overall system design and prototype efforts to date, including testing on critical elements of the system and field-testing in a collapsed structure environment. Future testing is envisioned with first responders to further evaluate the prototype design and collect data for future improvements. The vehicle design was shown to be effective for terrainability and access into small/vertical spaces, but future improvements in key areas (tethering, displays, etc.) are recommended to improve system performance. The project is being funded by DARPA (Defense Advanced Projects Agency) with the intent to transfer technologies from the military domain to the civilian first-responder application markets.
\end{abstract}

Keywords - robot, search, rescue, tether, rappel, locomotion

\section{INTRODUCTION}

The urban environment represents the most challenging application-arena for reconnaissance and recovery robots, irrespective of whether the structures are in pristine, or even worse, collapsed and crumbled configurations. The ability to access constrained and often layered environments (due to flooron-floor collapse) has been only possible in very limited scenarios. The challenge is evidenced in Figure 1 ,

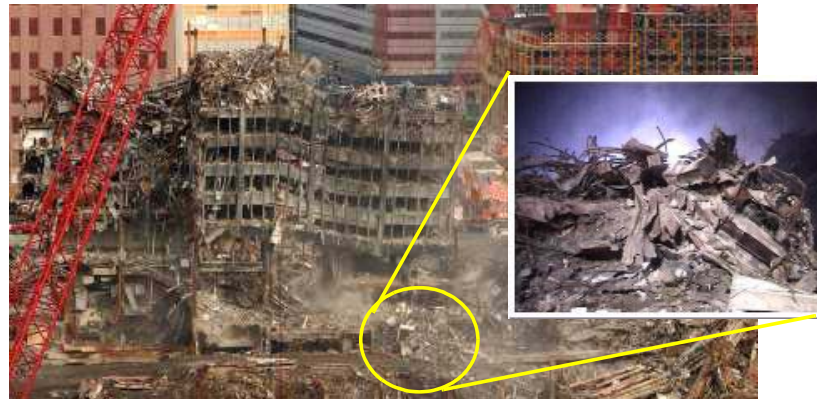

Figure 1 : Catastrophic Building Collapse - WTC Site on 9-11-2001 
which clearly shows the access and locomotion challenges that 'mechanized' rescue devices would face. Whether collapses are due to man-made or natural causes, the key questions that need to be answered, especially in the first 24 to 72 hours, are still the same: Are there any survivors and where are they? What is the structural integrity of the structure? Are there any hazardous conditions within the structure not clearly visible to first-responders?

Only since the 9/11 attack on the Pentagon and World Trade Center (WTC), have robots been used in such applications (CRASAR, DARPA, etc.) [1][2][4]. Even then, their application was fairly limited [8]. However, the use of robots is projected to grow once the technology becomes more mature, accepted, and more capable. Currently, the use of larger, wirelessly-controlled and battery-powered platforms limits the use of robots in cluttered, confined and long-duration applications. Tethered platforms (such as the Innuktun line of crawlers) have proved to be extremely valuable and usable, but since their spoolpoint is at the base, rather than at the robot, the range of deployment is limited, or restricted to fairly accessible (lower frictional drag) and more obstacle-free (no chance of snagging) situations.

\section{REQUIREMENTS AND SPECIFICATIONS}

In order to develop a more capable disaster-response robotic system for use in confined collapsedstructure access for survivor search, site-investigation and site-assessment, the following key attributes are deemed essential (in no particular order of importance):

- Provide for a small and light footprint

- Allow for long-term deployment of at least 12 hours

- Be capable of carrying crucial sensor-modalities (visual, chemical, etc.)

- Be capable of accessing and climbing up/down convoluted and confined spaces

- Be capable of real-time control of 'buried' ranges no less than $30 \mathrm{~m}$

- Be simple to use off a limited-function controller with a user-friendly GUI (Graphical User Interface)

- Be designed for rugged use and be affordable for civil-defense entities

We conducted a technology search that looked at numerous robotics platforms (commercial and R\&D platforms available through IRobot, Foster-Miller, Remotec, Innuktun, etc.)[3][5], and determined that none of these systems were designed explicitly with the collapsed-building internal-use scenario in mind. Most systems had constraints in terms of size, weight, endurance, locomotion capability, etc. [6][9].

These shortcomings needed to be overcome before a more usable and capable platform could be offered to first responders - one they would be willing to rely upon and use. We believe that SPIDAR, a new 
representative for self-tethering platforms [10][11], with articulated frame/suspension and reconfigurable running-gear (wheels, legs, treads) [7], has the potential to overcome the main drawbacks of current systems. In addition to its off-the-vehicle tether-spooling (laying/spooling down/up the tether), with data/power integral for long-duration missions, the vehicle will need to be a capable of deploying visual (visible and IR) and other chemical sensors $\left(\mathrm{CO}_{2}\right.$ emissions, $\mathrm{NH}_{3}$-detection, $\mathrm{SpO}_{2}$ blood-oxygen content, etc.) into real-world disaster scenarios.

Based on interactions with experts in the field of search-and-rescue, it became clear that many design decisions hinged on the trade-offs related to (i) system size to access the smallest possible openings, (ii) the need to overcome large obstacles (rubble) which is directly related to size, and (iii) the need to be able to adapt to the unpredictable terrain type and the need to probe to varying depths into collapsed structures and other locations (sewers, caves, ducts, etc.). The design trade-offs determined early on what size (tiny, small, medium or large) platform was utilized (trading off access-capability against obstacle-climbing capability) ${ }^{1}$, and what operator-selectable features were to be included in the design, to optimize terrain-handling abilities (locomotor-dependent) ${ }^{2}$ and probing-depth (related to tetherlength primarily if access is guaranteed $)^{3}$. The net outcome was the high-level performance requirements shown in Table 1, which were then tuned into system specifications for the prototype (see Table 2).

Table 1 : SPIDAR Performance Requirements

\begin{tabular}{|c|c|l|}
\hline CRITERIA & VALUE & \multicolumn{1}{c|}{ DESCRIPTION OR INTERPRETATION } \\
\hline \hline Size & Small & $\begin{array}{l}\text { As non-bulky as possible; } \\
\text { Small enough to fit through tight man-inaccessible spaces }\end{array}$ \\
\hline Weight & Light & Single-person one-hand hanging-portable \\
\hline \multirow{2}{*}{$\begin{array}{c}\text { Terrain } \\
\text { Ability }\end{array}$} & \multirow{2}{*}{ Extreme } & $\begin{array}{l}\text { Use of retractable tensile member for climbing/rappelling; } \\
\text { Forward/reverse in extreme terrain; } \\
\text { Use in complex interconnected (collapsed) man-made spaces; } \\
\text { Able to climb over/onto varying/large size obstacles, into/though rubble, } \\
\text { sewers, tunnels, ducts }\end{array}$ \\
\hline \multirow{2}{*}{$\begin{array}{c}\text { Tether } \\
\text { System }\end{array}$} & Multiple & Strength-member, power-supply \& communications link \\
\cline { 2 - 4 } & Rugged & Sharp-bend (under load) survival w/o loss \& fatigue-endurance \\
\hline Endurance & Maximize & Tether-tension and pay-out distance \\
\hline Range & Use of long-duration power source; on- or off-board \\
\hline Integration & Various & At least 30m if not more \\
\hline Locomotor & Various & Wh-board sensing, communications \& processing \\
\hline
\end{tabular}

1. A small/tiny platform capable of accessing a small opening is not as capable if it can not overcome large (w.r.t. the vehicle size) obstacles (internal and not visible externally) in its way, rendering its size-attribute unusable.

2. There is no single locomotor capable of handling all terrain types - these terrain types are varied and not known beforehand and thus providing the operator with the ability to adapt on-site is an advantage over hard-designed (non-modular) systems.

3. The ability to decide on-site (by the operator) what vehicle configuration is best used to minimize size and weight yet be able to probe deep into the 'buried' structure, is another modularity attribute that provides substantial advantages over other more fixed-design non-modular systems available today or under consideration/design. 


\begin{tabular}{|c|c|l|}
\hline CRITERIA & VALUE & \multicolumn{1}{c|}{ DESCRIPTION OR INTERPRETATION } \\
\hline \hline \multirow{2}{*}{$\begin{array}{c}\text { Command } \\
\text { \&Control } \\
\text { (C\&C) }\end{array}$} & $\begin{array}{c}\text { As } \\
\text { needed }\end{array}$ & Handling all sensory feedback and control data \\
\cline { 2 - 3 } & $C P U$ & Processing all data and real-time control of all actuation \\
\hline Control Unit & - & Operator video display \\
\cline { 2 - 3 } & Interface & Power and Communications Interface to the tether \\
\hline \multirow{2}{*}{$\begin{array}{c}\text { Sensor } \\
\text { Payload }\end{array}$} & Video & Cameras (3 - front/left/right) \& lights for $360^{\circ}$ 'surround'-vision \\
\cline { 2 - 3 } & Sound & Microphones (3 - front/left/right) \\
\hline
\end{tabular}

Table 2 : SPIDAR System Specifications

\begin{tabular}{|c|c|c|c|}
\hline Application Areas & \multicolumn{3}{|c|}{ Collapsed Buildings, Caves, Sewers, Ducts, Contaminated } \\
\hline Size & $71 \mathrm{~L} \times 41 \mathrm{~W} \times 10 \mathrm{H}\left[\mathrm{cm}^{3}\right]$ & Weight & $<12.5 \mathrm{kgs}$ \\
\hline Speed & $\leq 0.3 \mathrm{~m} / \mathrm{sec}[1.13 \mathrm{~km} / \mathrm{hr}]$. & Power & $120 \mathrm{VAC}, 4.4 \mathrm{~A}$ \\
\hline Range & 30 - 60 or more ${ }^{a}$ meters & Operations & Invertible ${ }^{b}$ \\
\hline Tether & Power, Data \& Tensile ${ }^{c}$ & Communications & $100 \mathrm{Mb}$ Ethernet $^{d}$ \\
\hline Video & Color, $15 \mathrm{fps}^{e}$ & Lights & White LEDs \\
\hline Ruggedness & $10 \mathrm{~g}$ impacts $f$ & Immersion & IP65 rated \\
\hline $\begin{array}{l}\text { Tension } \\
\text { Control }\end{array}$ & \multicolumn{3}{|c|}{$\begin{array}{l}\text { Tension-relief capstan-drive with slip-clutches and thresholded directional } \\
\text { motor current \& torque controller with tension-saturation relief }\end{array}$} \\
\hline Electronics Arch. & \multicolumn{3}{|c|}{$\begin{array}{l}\text { Off-board WIN-based embedded PC with an on-board 32-bit LINUX-based } \\
\text { SBC with on-board 8-bit distributed CPUs with real-time software kernel }\end{array}$} \\
\hline Running Gear & \multicolumn{3}{|c|}{ Wheels, Tracks, Legs (ellipto, spoke) \& any hybrid combination } \\
\hline Sensors & \multicolumn{3}{|c|}{$\begin{array}{l}\text { Microphones (2), Speakers (2), Low-lux CMOS Cameras (3+) with } 120^{\circ} \\
\text { FOV Lens - full } 360^{\circ} \text { spherical }^{g} \& \text { pointing }\end{array}$} \\
\hline Locomotion & \multicolumn{3}{|c|}{ Any surface, vertical climbing/descent; tether assisted } \\
\hline Articulation & \multicolumn{3}{|c|}{ Postureable chassis for extreme climbing, ledge handling \& inspection ${ }^{i}$} \\
\hline OCS Controller & \multicolumn{3}{|c|}{ Mini-briefcase OCS ${ }^{j}$ with optional handcontroller } \\
\hline
\end{tabular}

a. achieved through the in-line coupling of tether-module range-extender units, which consist of a separately-housed replica of a TMS (as many as needed to achieve a specific range)

b. can run right-side up or inverted

c. teflon-jacketed multi-conductor STP copper cabling with filler \& Kevlar tensile fiber-mesh

d. digital \& bi-directional; implementing reduced-set TCP protocol as per 802.3 standard

e. digital MPEG-4 compressed

f. achieved through isolation and encapsulation - proprietary method applied \& proven in Dragon Runner

g. achieved thru multi-camera views with digital multi-view cycle-thru update

h. through the use of pitcheable posture-, head- and camera-modules

i. both chassis, sensor-head and camera-module are independently postureable to allow up/down climbing and downward crack- and edge-inspection

j. highly portable and includes a tether-termination anchoring setup to relief tether-tension to the OCS 


\section{SYSTEM DESIGN}

This section describes the current design for the SPIDAR system. It addresses the main specific subsystems and overall system descriptors that were deemed essential and were identified as main design drivers.

\section{Overview}

An overall perspective of the vehicle platform, is shown in Figure 2, depicting the multi-segmented, allwheel drive (AWD) multi running-gear configuration (shown here with wheels) system design:

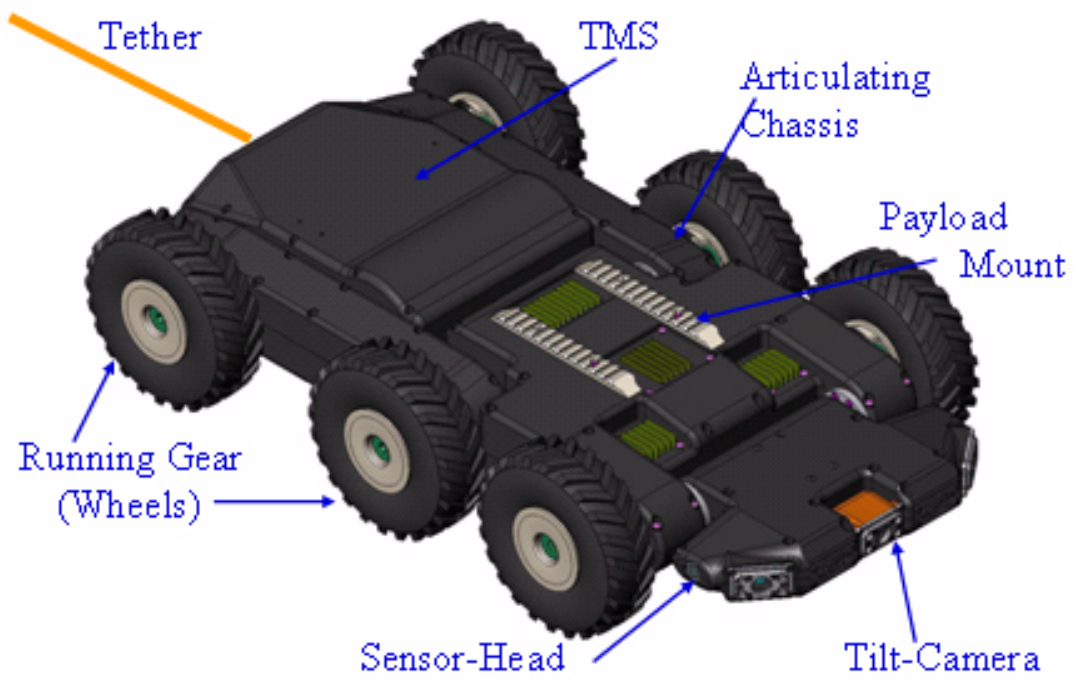

Figure 2 : Overall external CAD view of the SPIDAR vehicle platform

Notice that the overall design of the system allows the platform to be fully invertible and operate in either orientation - video imagery and driving-commands are automatically flipped (based on accelerometer feedback), and the sensor-head on the platform can rotate so as to allow the same field-of-views irrespective of the (rightside-up/upside-down) orientation of the platform itself. In other words it does not matter how the platform lands or winds up oriented when being deployed. The size of the platform is depicted in Figure 3 and exhibits a net volume of $0.018 \mathrm{~m}^{3}$ and a total weight of $11.2 \mathrm{~kg}$.

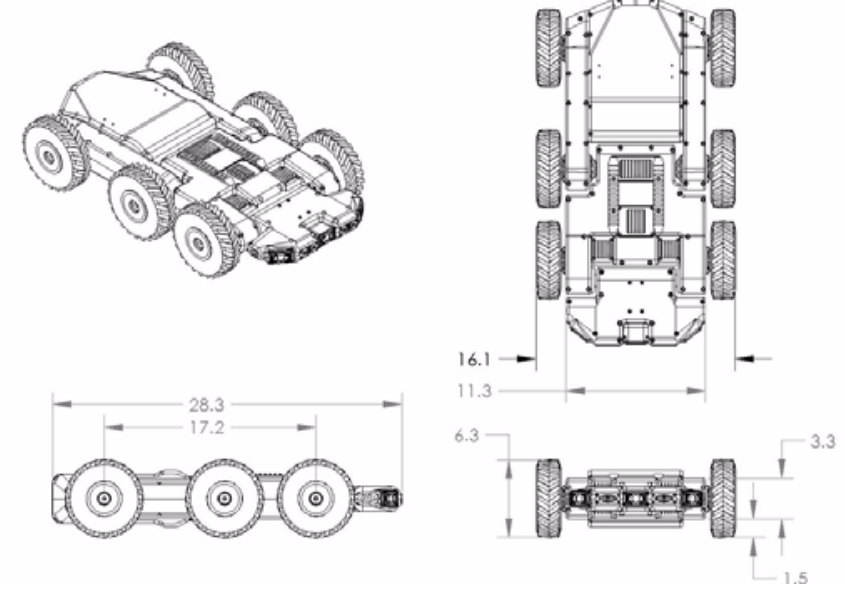

Figure 3 : Overall SPIDAR baseline vehicle platform dimensions 
The vehicle chassis is split to allow for posturing of the frontal section for improved climbing and sensory inspection activities. The running gear is exchangeable with different configurations such as wheels, tracks and legs.

The main elements of the SPIDAR system are all depicted in a top-shell-off exploded view in Figure 4, which are detailed in the following subsections.

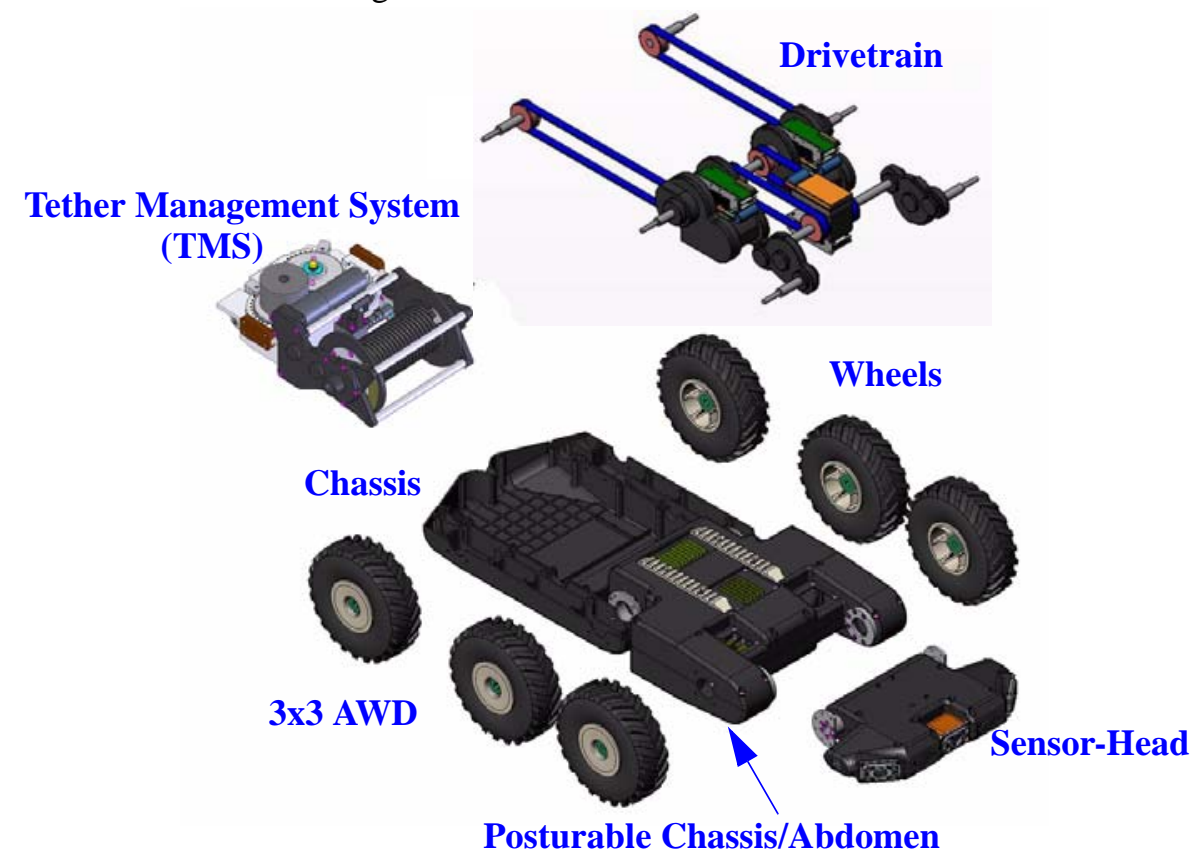

Figure 4 : Internal view of the main vehicle platform subsystems

\section{Mono-coque Chassis and Articulation (Chassis \& Sensors)}

The housing/shell (also termed chassis) is the structural element of the vehicle. It was designed to be mirror-image identical (top/bottom) so that it can be injection-molded in a fiber-reinforced thermoplastic to endure abuse and be light and low cost to reproduce or replace. The shell is split into a fixed-axle rear compartment and an actively postureable front-end - this is to allow for larger-sized obstacle climbing ability (ledges, beams, boulders, etc.) and controlled transitions from vertical to horizontal during climbing and rappelling motions. Articulation of the sensor-head allows for the operator to view the entire surroundings of the vehicle under real-time conditions. A visualization for the articulation of the chassis-abdomen and the sensor-head, are shown in Figure 5. 

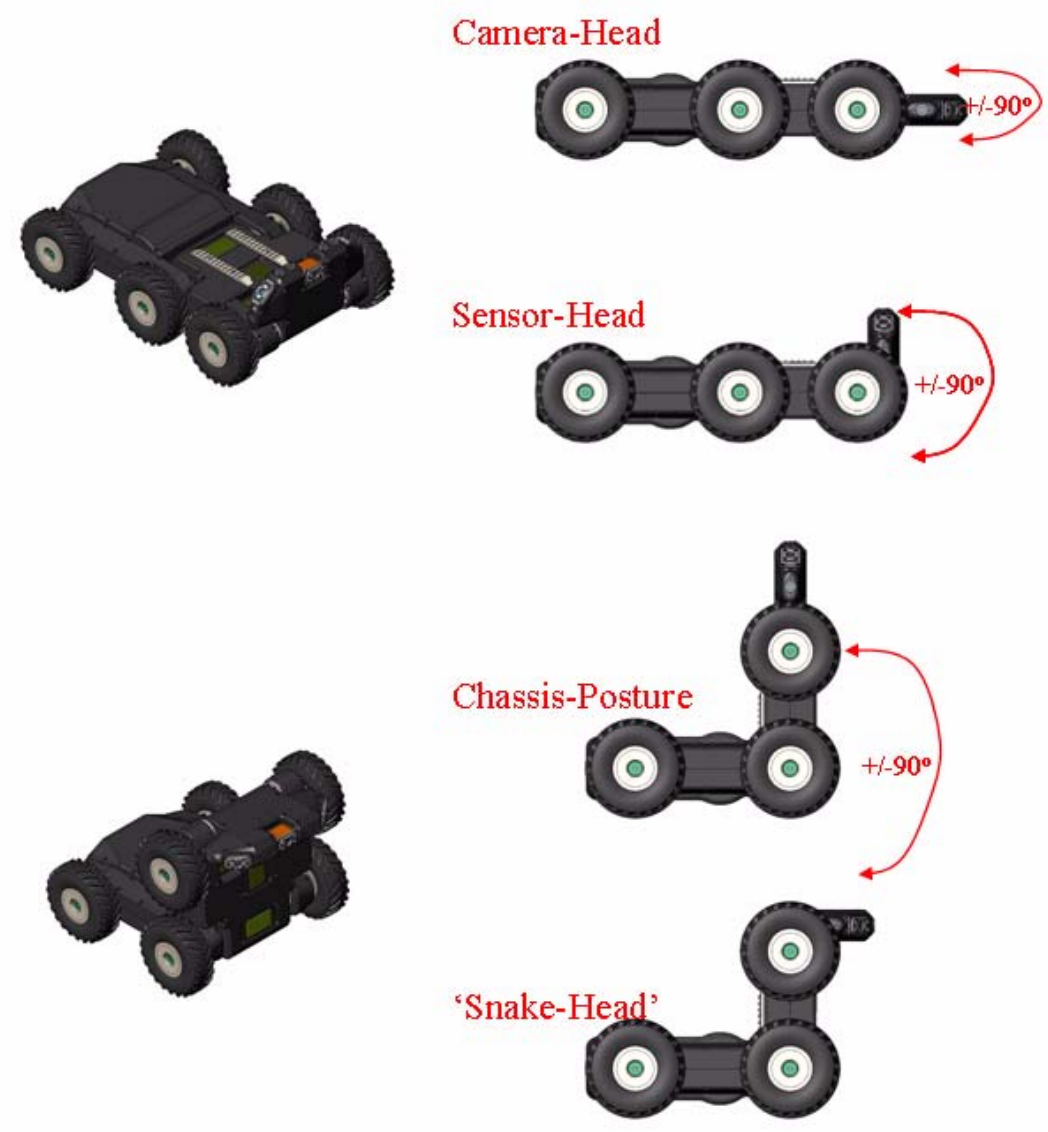

Figure 5 : Chassis and sensor-head articulation for SPIDAR

\section{Visual Sensing and Fields-of-View (FOVs)}

The internal environmental sensor-suite for the SPIDAR platform consists of visual, audio and motion sensors. The video imaging sensors in the robot platform are both in the front (3 ea.) and in the rear (1 ea.). Based on the capability to posture the camera-unit, sensor-head and chassis/abdomen of the robot, the system is capable of viewing and imaging a large FOV around itself. Using simply the three forward cameras without any articulation, a digitally-stitched image covers a $120^{\circ} \mathrm{FOV}$ truncated conical region (see OVERALL in Figure 6 on page 8). Pitching the sensor-head thus would provide a swept conical FOV both upward and downward (looking over and down over a ledge), as well as backwards (see BACWARD-LO). Posturing the chassis/abdomen as well as the sensor-head, can provide perspective views both right in front of the vehicle as well as to its arrears (see FORWARD/BACKWARD-HI).

A view of the different FOVs for the forward camera sensors ${ }^{4}$, as depicted by projected viewing 'cones'

4. we are omitting the rear-facing camera, as its main purpose is to check on the tether spooling/layout process and assist in backing-up driving, which is considered a very small portion of the expected S\&R mission profile. 
under different camera, sensor-head and chassis articulation configurations as discussed above, are shown in Figure 6.
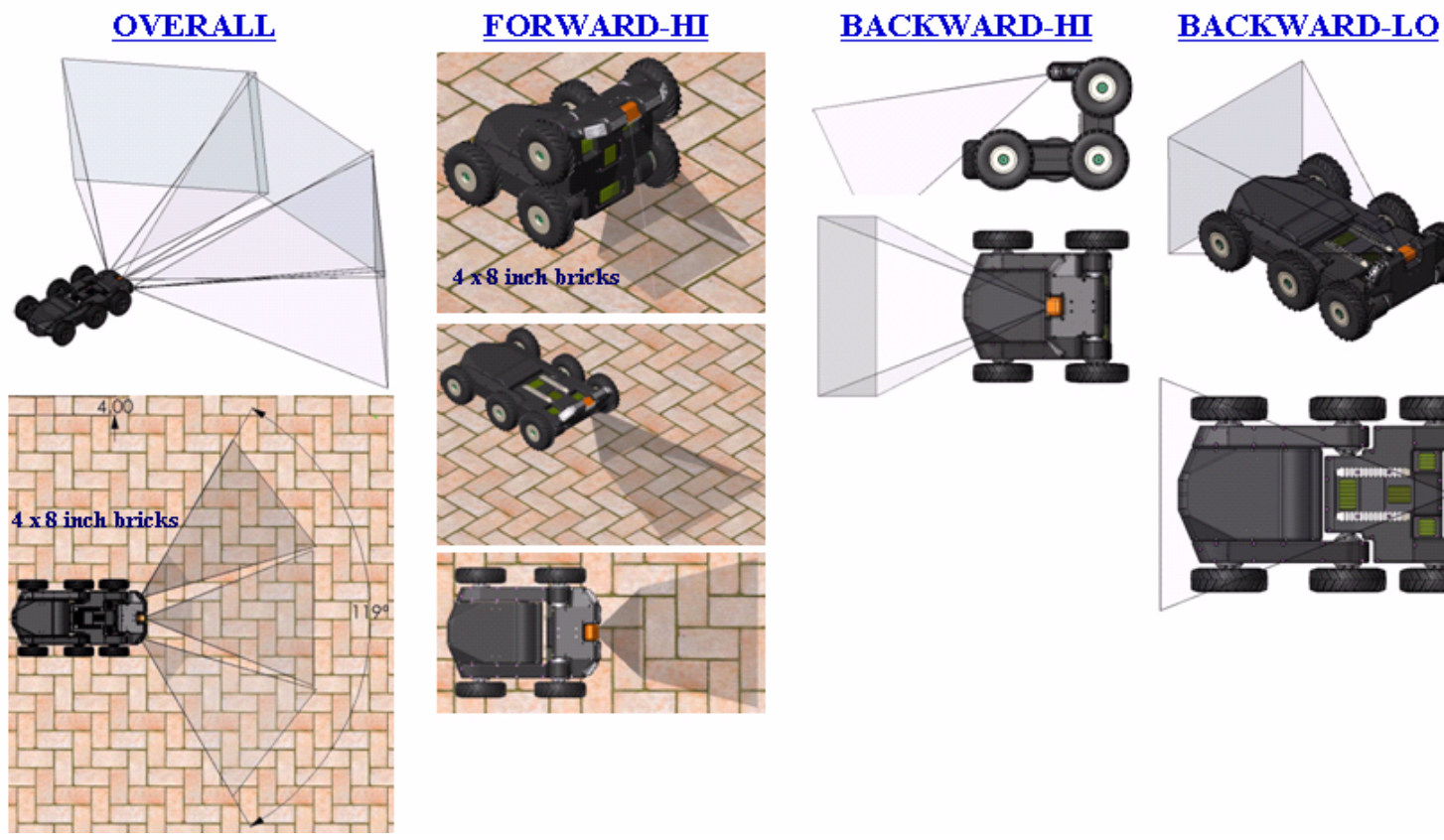

Figure 6 : SPIDAR robot platform FOV configurations for forward camera(s)

\section{Vehicle Chassis - Integration \& Posture Articulation}

The main chassis element of the SPIDAR platform houses the main drive-motors and reduction gearboxes, as well as all the transfer drives and the chassis-posture drivetrain. The electronics to drive the motor power-stages (ESCs) and the local low-level 8-bit control microprocessors are mounted in a heatsink stack, which is sandwiched between the two thermoplastic housing shell-halves. An assembled, internal and close-up view of the different elements within the (abdomen) chassis section of the SPIDAR vehicle, are shown in Figure 7.

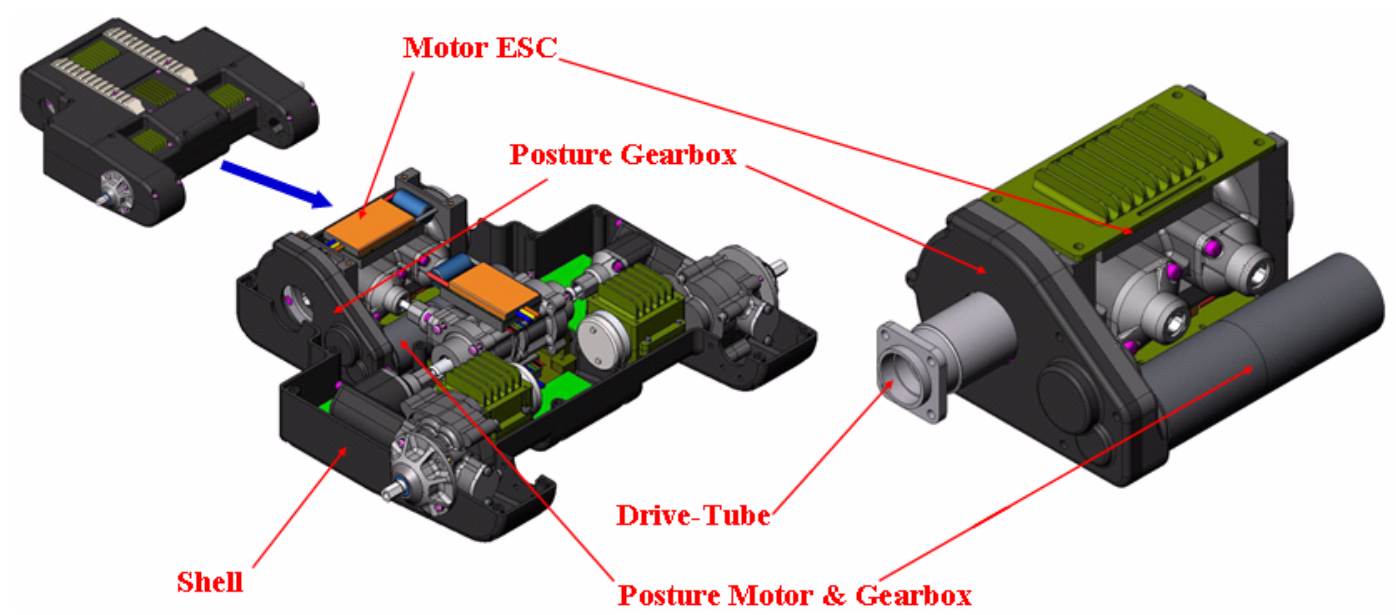

Figure 7 : SPIDAR vehicle (abdomen) chassis packaging and posture drive details 


\section{Sensor-Head - Integration and Articulation}

The SPIDAR vehicle platform's sensor-head is the brain for the entire platform. It not only houses the main sensing elements (cameras and microphones), as well as the camera and sensor-head posturing/ articulation motor-gear box servos, but also contains the main 32-bit SBC, as well as any local 8-bit micro controllers. The assembled and internal packaging-views are shown in Figure 8:

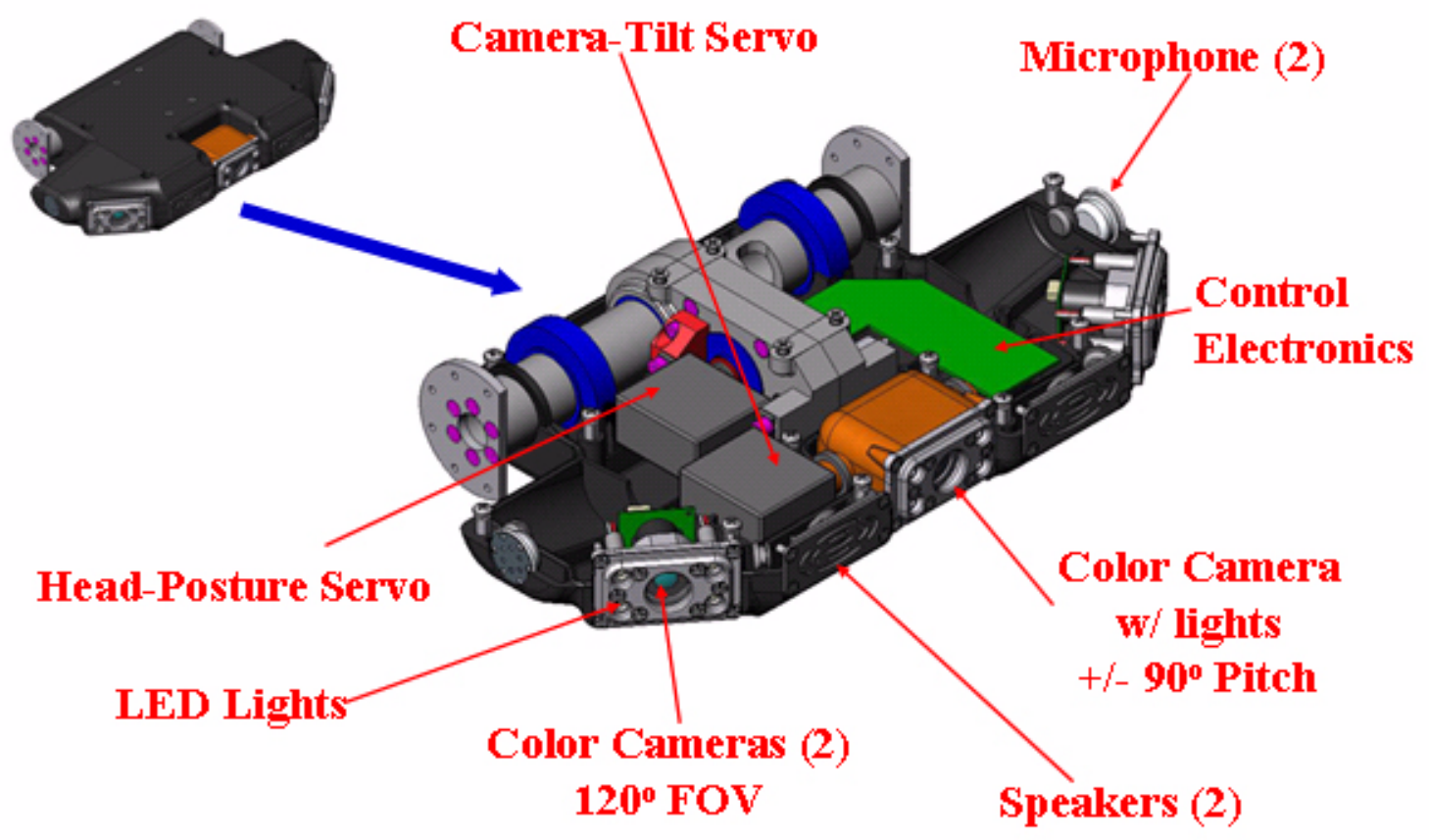

Figure 8 : SPIDAR vehicle sensor-head packaging and articulation drive details

\section{Drivetrain}

The drivetrain for the vehicle is based on a dual-motor/gearbox arrangement, coupled with rear-ward and forward running drive-shafts and pulley/belt combinations, as depicted in Figure 9.

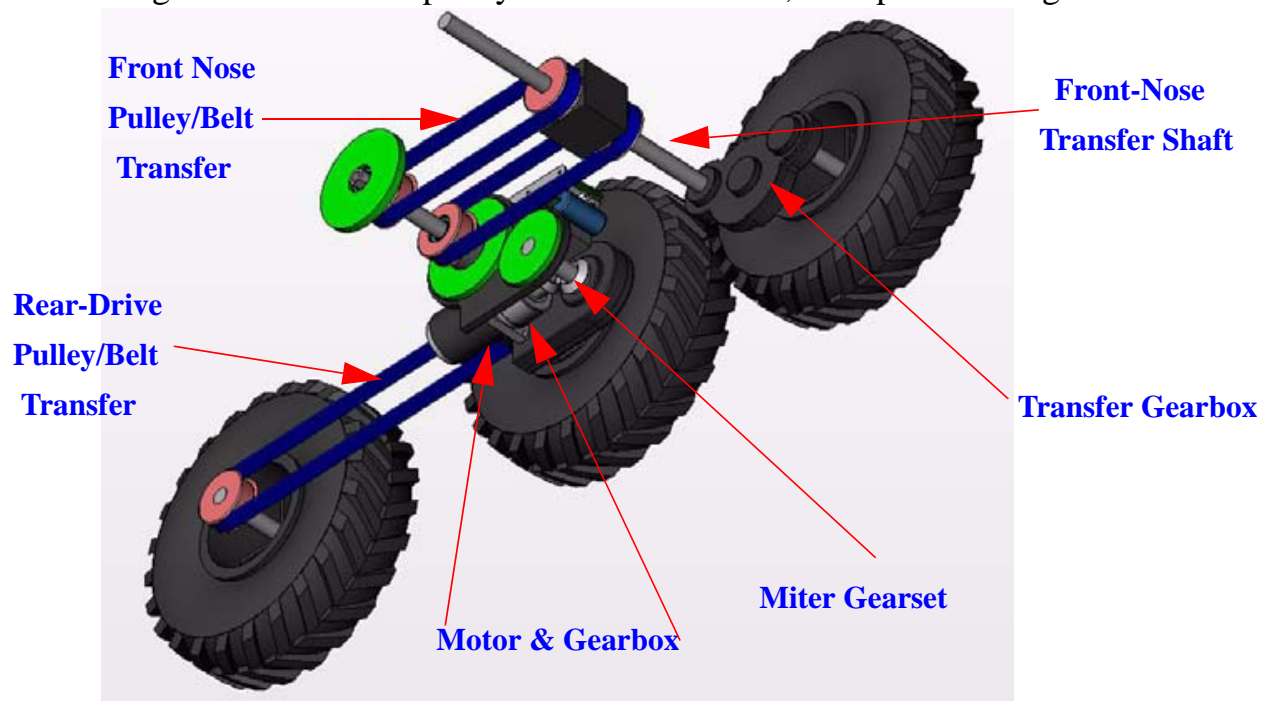

Figure 9 : Pre prototype drivetrain design layout 
This design allows for the minimal-weight implementation of skid-steer drive in a multi-wheeled articulated-frame vehicle. An additional motor/gearbox/miter-gear drivetrain is used to articulate the front housing of the vehicle, achieving a postureable chassis/abdomen (see Figure 5). Miniaturized servo-actuators are used to provide articulation for the sensor-head, as well as the centrally-located forward-looking pitch-camera (driving and up-close inspection), to increase the FOV in as compact a platform-design as possible.

\section{Locomotion or Running-Gear}

The running gear, as shown in Figure 2, depicts a set of six wheels that are driven by a common set of two motor-drivetrain combinations in a skid-steer fashion. The design also supports running gear variations with a track, creating a half-track vehicle to show the versatility of the SPIDAR system design to suit the running gear to a variety of conditions. In addition, a legged configuration based on a shockabsorbing, climbing-hook spoke-leg design is possible as yet another hybrid running-gear alternative. Running-gear configurations conceived to-date are summarized in Figure 10.

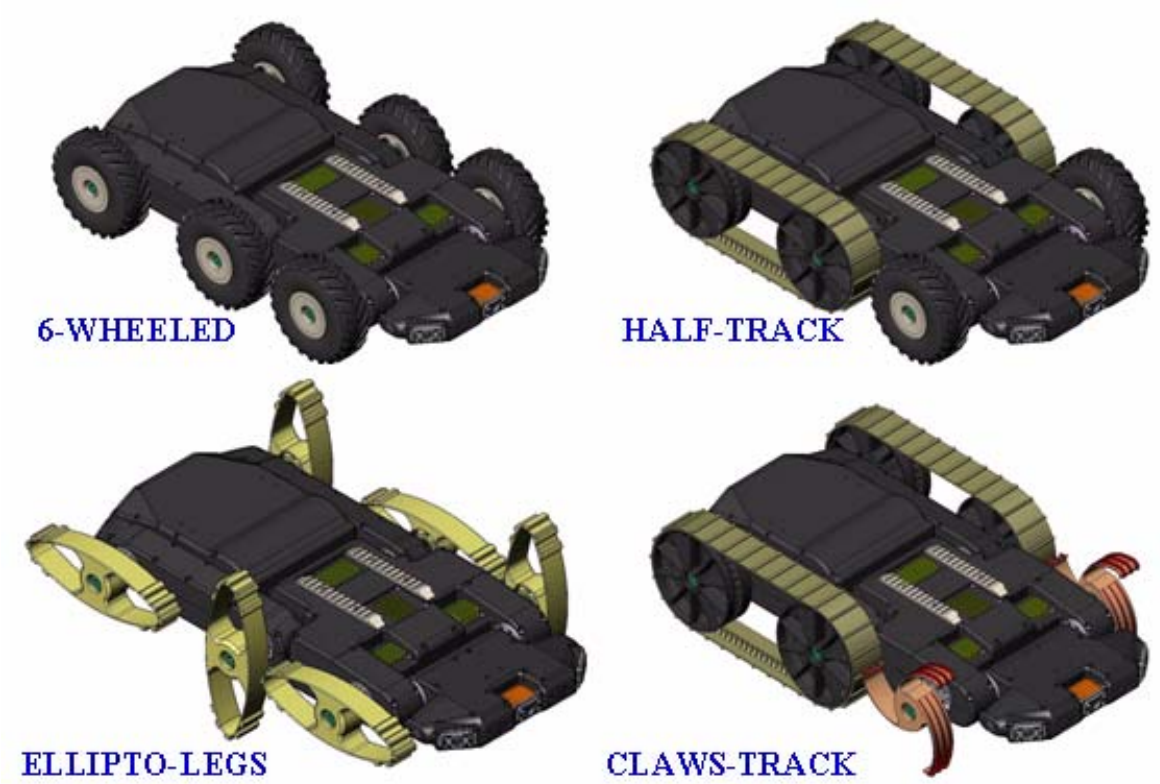

Figure 10 : Possible running-gear configurations for SPIDAR

\section{Tether Management System (TMS)}

The TMS is the core of the rappelling capability for SPIDAR. The TMS contains the tether-drum (with sliprings, etc.), drum-drive and levelwind (to force orderly wind/unwind under tension), as well as guides to feed the tether into the capstan-drive that provides for the pay-in/-out motions under all design- 
loads. All motions are instrumented (position and velocity) with the capstan having a strain-gauge tension-monitor; both drum- and capstan-drive have over-load spring-wrap slip-clutch protection devices. Thes protection devices offer a fail-safe design feature to allow for over-tension protection (during precipice free-fall) and free-fall breaking action. The design and layout of the TMS is shown in Figure 11, showing the tether-path and wound layer approach on the grooved drum, including the levelwind and actuation gearbox motors.

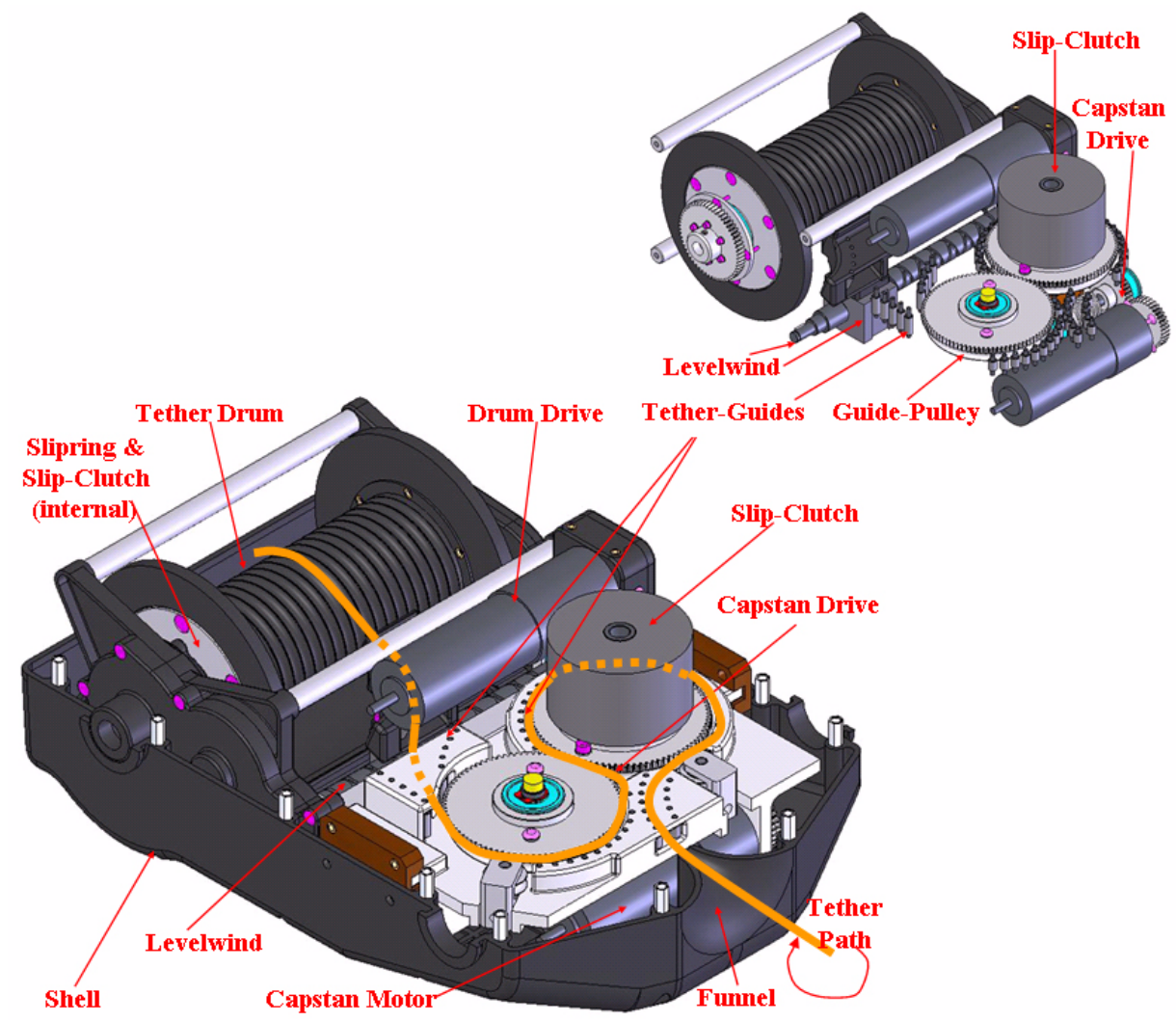

Figure 11 : TMS design and layout

\section{Tensile Power/Data Tether}

The copper-based multi-conductor tether design was developed by a specialty underwater cabling company in California. The cross-section for the tether and the design specifications for the same, are shown in Table 3 and in Figure 12.

Table 3 : Multi-conductor Copper-based tether specifications

\begin{tabular}{|c|c|}
\hline CRITERIA & SPECIFICATIONS \\
\hline Overall Diameter & $0.43-0.495[\mathrm{~cm}]$ \\
\hline Weight & $0.021[\mathrm{~kg} / \mathrm{m}]$ \\
\hline Peak Tension Load & $68[\mathrm{kgs}]$ \\
\hline Breaking Strength & $340[\mathrm{kgs}]$ \\
\hline Bend Radius & $5.1[\mathrm{~cm}]-$ MAX \\
\hline Outside Jacket Material & Polyurethane - 0.064 [cm] thick - Orange Color \\
\hline Tensile Member Material & Woven Kevlar Yarn \\
\hline Conductors & 3 pairs; \#28 AWG, Sn-plated Cu, 300V rated Polypro \\
& insulation; twisted; heat-extruded \\
\hline
\end{tabular}




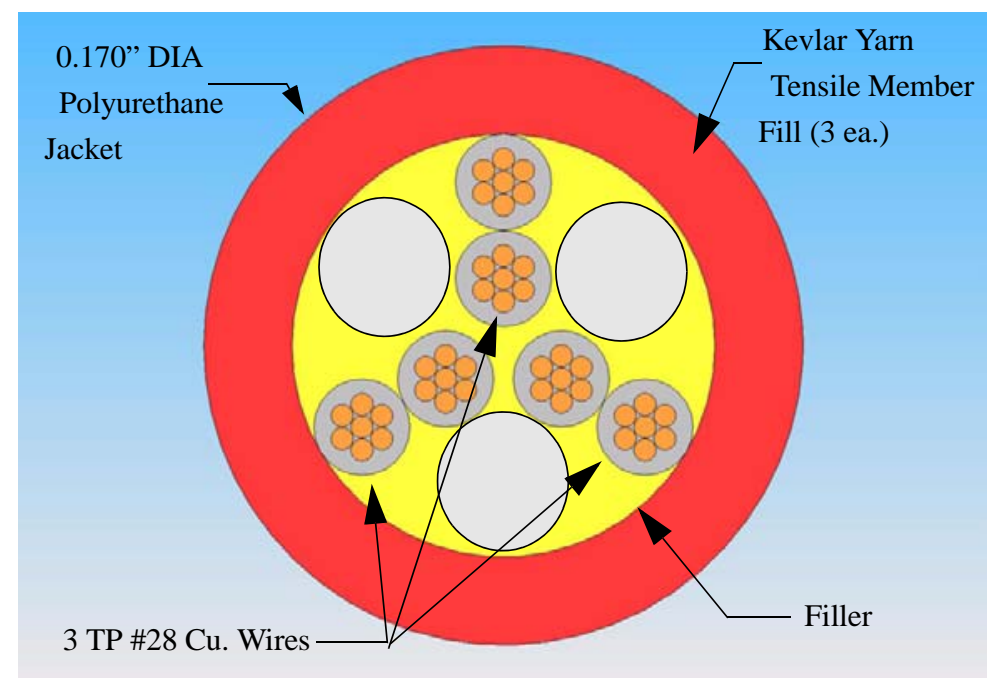

Figure 12 : Cross-section of proposed multi conductor copper-based SPIDAR tether.

Note that the above design shows the tensile members (Kevlar mono-fibers), arranged around the conductors, minimizing cross-section, increasing flexibility, etc. This does however lead to a nontorque-balanced tether, which we expect to be of no consequence, as the cable-flexibility will be so high that its tendency to loop on the ground (rather than lying flat as spooled out) should not cause any additional snag-points nor make it any harder to reel back in.

\section{Computing, Communications and Electronics Architecture}

The power and data flow in the SPIDAR system is based on a standard parallel data/power architecture over a connecting tether to a control console, powered through an AC generator, as depicted in Figure 13:

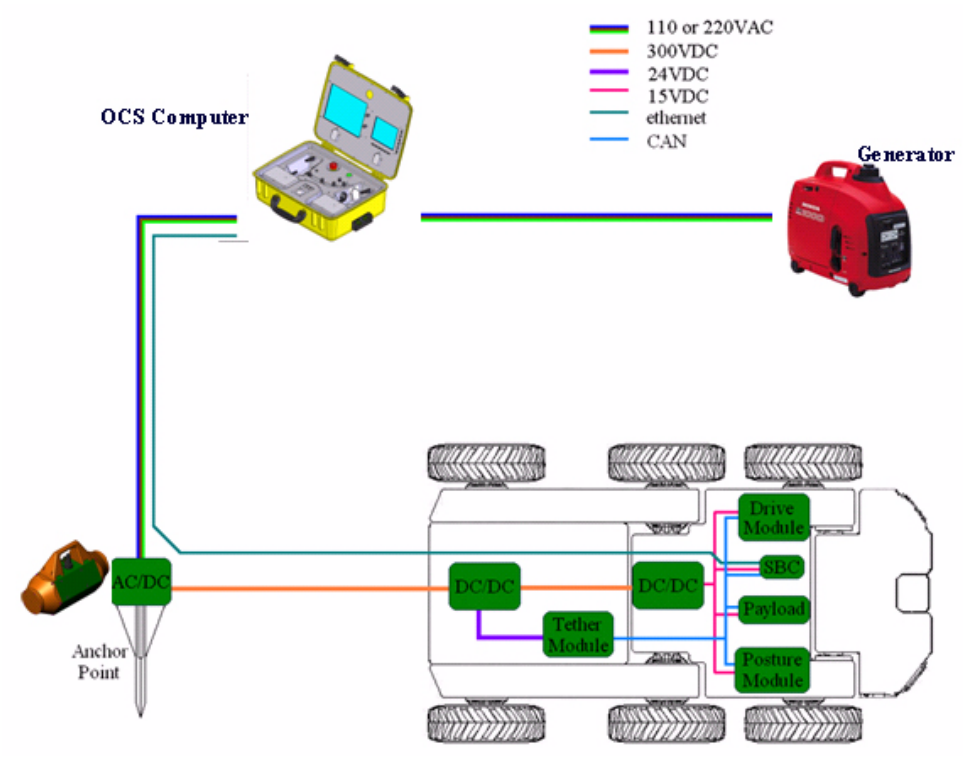

Figure 13 :Power and Data Architecture and Flow 
- Power: AC power from the generator runs the OCU as well as the robot through an AC/DC converter in the system anchor. The power is again DC-converted on the robot and fed to the motors (48 VDC) and a set of distributed 8-bit processors (12, 5 VDC).

- Data: A 32-bit Single-Board-Computer (SBC) in the robot handles all supervisory control, including video digitization and communications with the topside OCU over wired ethernet (802.3). Another SBC in the OCU performs all display and control interface I/O functions, allowing for real-time control of the platform.

\section{SPIDAR Software}

\section{- Overall Modular \& Distributed Software Flow}

The software architecture for the SPIDAR system is based on a standard distributed process architecture. The main computers, running the Linux OS, are located (i) in the OCU case and (ii) the vehicle, interconnected over a wired (802.3) ethernet data-link. The OCU handles all input-device I/O, videorendering and graphical status display, as well as safety heartbeat and all ethernet data-packet parsing. The Vehicle SBC acts as the digital data funnel, taking digital (MPEG-4) video-packets and status-data and parsing them onto the ethernet link, while forwarding all commands from the OCU over a standard protocol onto the CAN-bus to the different distributed microprocessors. This architecture is depicted in Figure 14.

\section{- Main Software Control Loops}

The main software control loops running on the 8-bit vehicle-embedded and distributed microprocessors, apply to the drive-, tether, posture- and head-modules. These loops and the main realtime tasks running on each of these microprocessors under the ATK-proprietary 8-bit RT kernel, are depicted below in Figure 15 in a highly simplified representation. The main logic for the main I/O control loops within each of these microprocessors is detailed in several succeeding subsections. 
SPIDAR: Self-rappelling Robot System for Inspection And Reconnaissance in Search and Rescue Applications

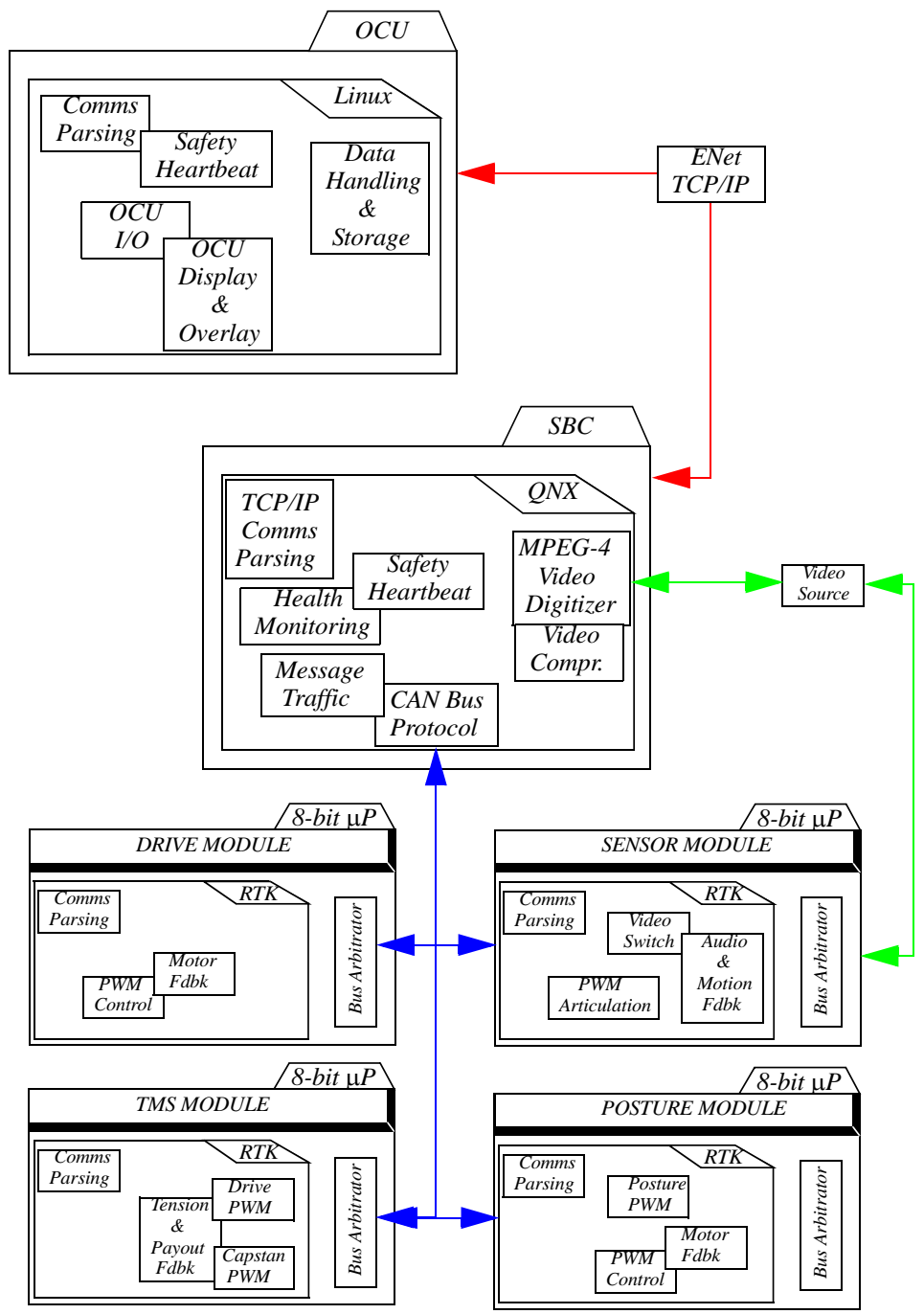

Figure 14 : Overall high-level software architecture and task-flow diagram for the SPIDAR system

DRIVE

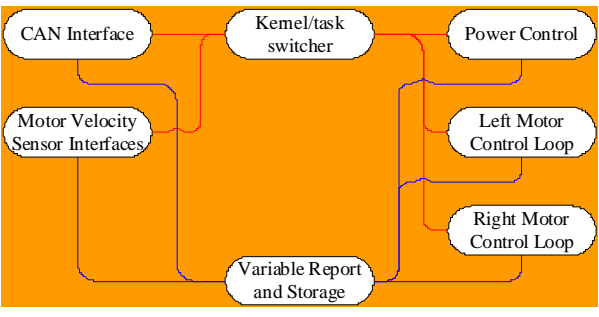

\section{TETHER}

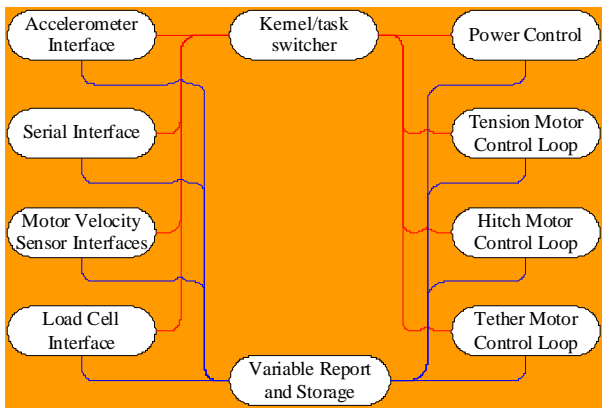

POSTURE

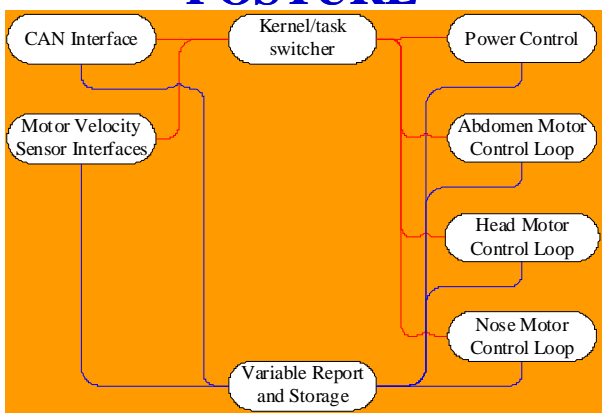

\section{HEAD}

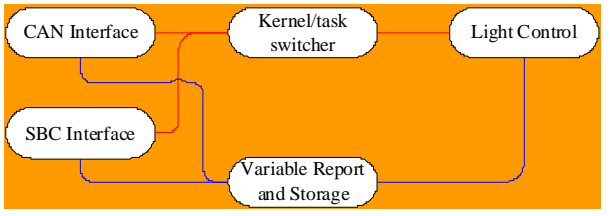

Figure 15 : Four main control loops running aboard the SPIDAR platform 


\section{- Motor Control Loop - Drive, Posture \& Tilt}

The SPIDAR drive system utilizes the latest generation of ATK-proprietary ESCs, capable of performing position/velocity control. Hence an initialization is required upon start-up (menu re-select), after which the CPU-resident control algorithm runs a straightforward PID-controller based on a desired position or velocity command. This capability is also reflected in the ability of the OCU, where a joystick can be used as a rate-(velocity) input device, but other buttons and dials can be used as position-input devices to for instance control the orientation-angle of camera, sensor-head or even chassis-articulation. The hardware is thus capable of switching dynamically between these two, based on an assignment command from the SBC (from the OCU). The control flow of this motor-driver loop is thus generic and applies to all drive-systems, whether for locomotion, posturing (chassis/abdomen and sensor-head) and camera-tilt. A depiction of the PID-loop mentioned above is shown in Figure 16.

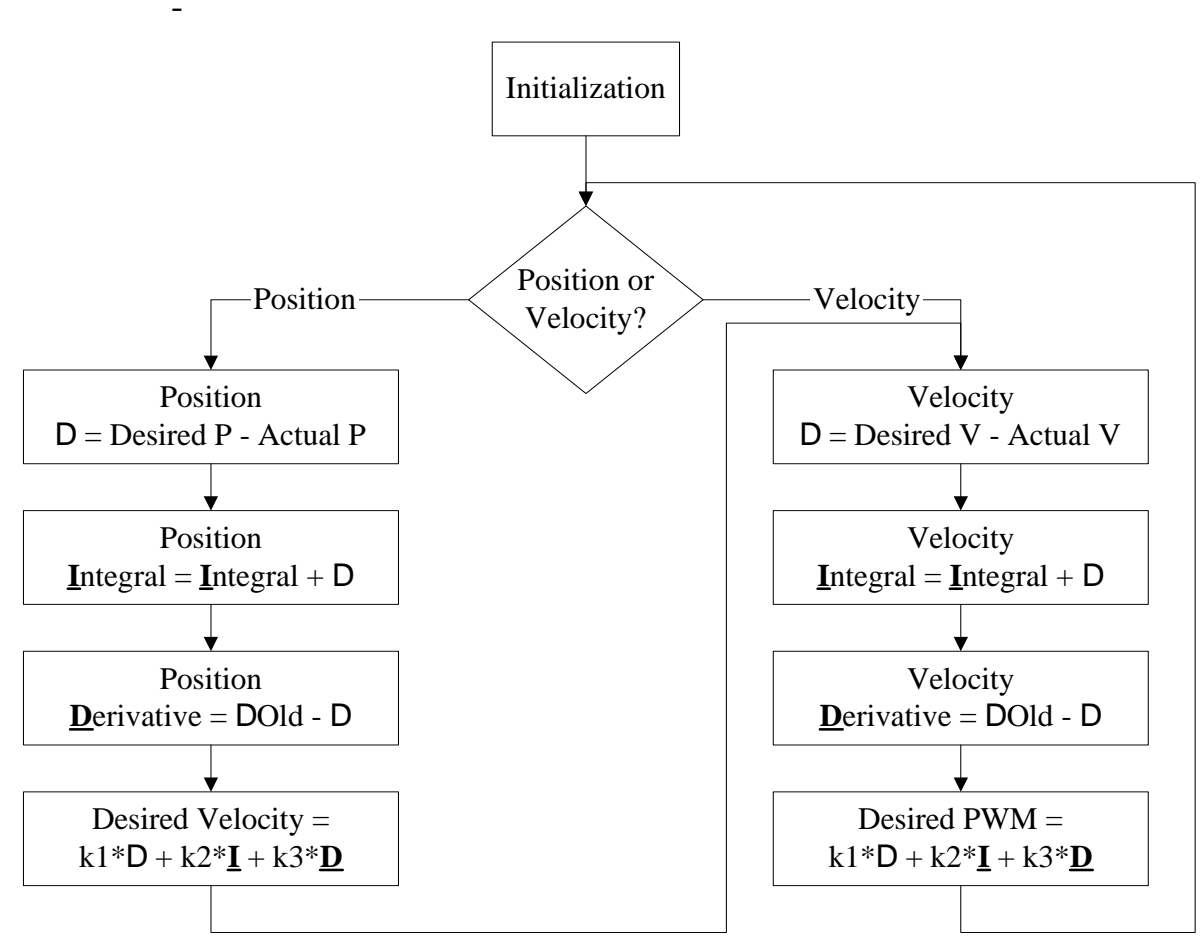

Figure 16 : Logic flow-chart diagram of the main motor control algorithm loop for motor-drive/-posture/ -tilt control of SPIDAR

\section{Tether Control Loop}

The tether control loop is by far the most complex of the control-loops running on the SPIDAR platform. The flow-diagram for the control-loop, as depicted in Figure 17, is best described as follows:

- The user is able to manually override the control-loop thereby allowing for pay-out or takeup, which is typically done using the rear-facing camera to take possible slack out of the tether before proceeding into an area where drop-offs are possible and thus tether-slack could be an issue with excessive free-fall and tether overload.

- The algorithm checks for fall-detection using its on-board accelerometers. If no fall is presumed, the tether algorithm checks to make sure the output tension does not exceed a 
preset minimal amount that was determined to always keep a minimal amount of tension on the tether to avoid excessive pay-out for reasons mentioned in the above bullet. Hence this is the typical operating mode in which the vehicle is simply commanded to drive and the tether tension is gauged as to whether there should be pay-out or not. Hence there is no coupling required between drive and pay-out/-in commands as it can be rather complex to coordinate in the absence of heading and true ground-progress sensing. It is simply paramount in our environment to not leave excess slack tether on the ground as it can cause a system failure should the robot want to rappel or suddenly free-fall.

-If fall was detected, the tether controller will base its pay-in/-out direction and rate based on tension measured, until it achieves a maximum tension level, correlated to the weight of the vehicle in free-space. Any impact loads due to limited free-fall will be compensated by the slip-clutch, in order to avoid tether-failure, as no algorithm could possibly be fast enough to react actively to keep the tension below the tether's tensile breaking strength.

The above algorithm is thus simple yet very effective due to the coupling of simple sensory input, coupled with mechanical protection levels and coupled spooling of the drum-/levelwind system that eliminates any potential of platform-internal tether foul-up, mis-winding or other potential winding mishaps.

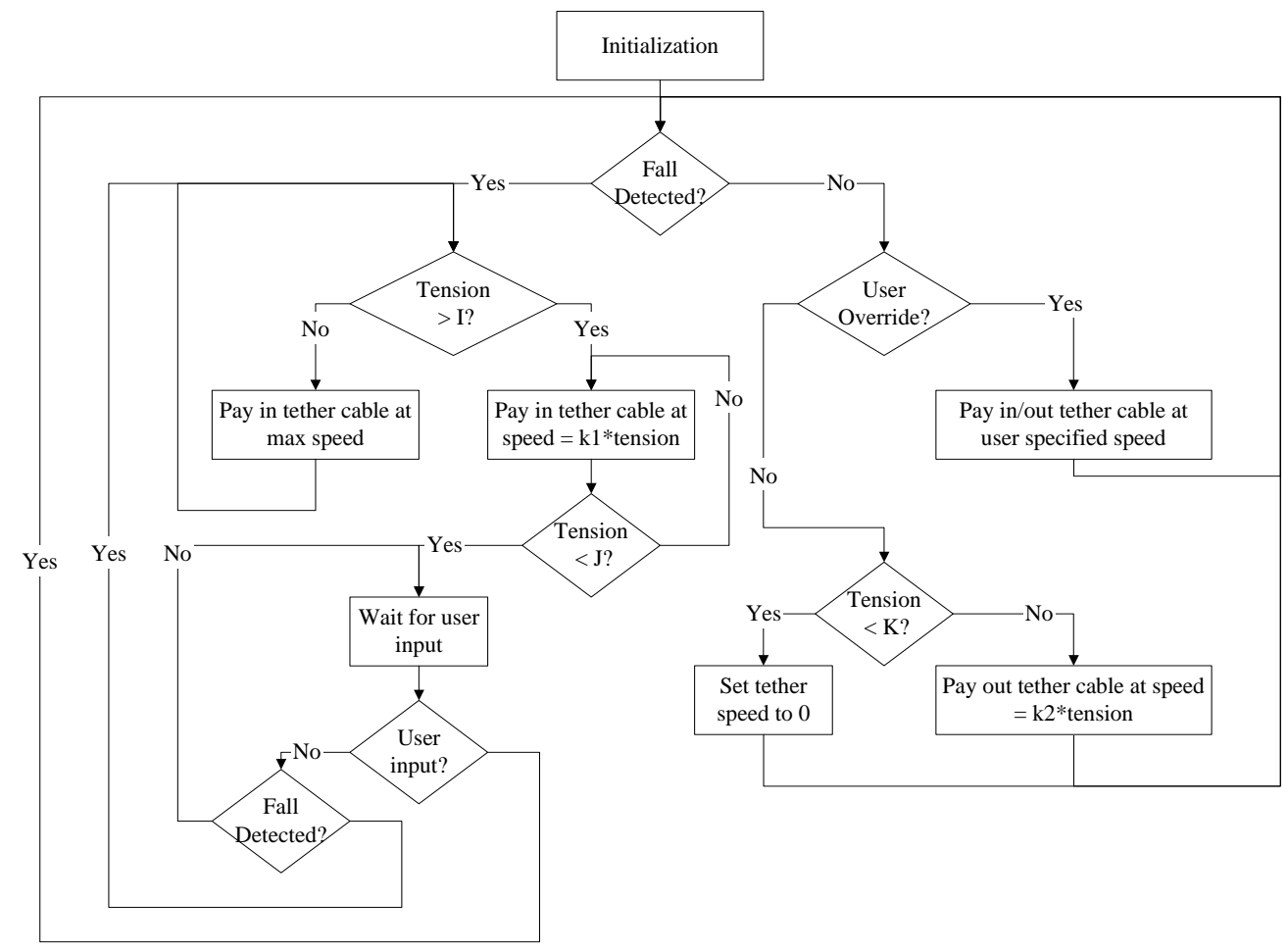

Figure 17 : Logic flow-chart diagram of the main tether control algorithm loop for tether pay-in/-out control of SPIDAR 


\section{Operator Control Unit (OCU)}

The OCU is based on a ruggedized case containing removable input-devices and video and computer feedback displays arranged as shown in Figure 18. The joystick-elements are removable for more operator freedom, and the unit is intended to be configurable in single- or dual-screen modes. Joysticks are used for the vehicle and payload separately. 110 VAC is converted in the case to usable voltages to drive all computing (PC-104 Pentium stack), displays, and routed to the anchor. Two separate displays can be used for video and computer touchscreen input. Individual dials allow for posturing control and USB ports are provided for video/image/data download and (real-time) recording.
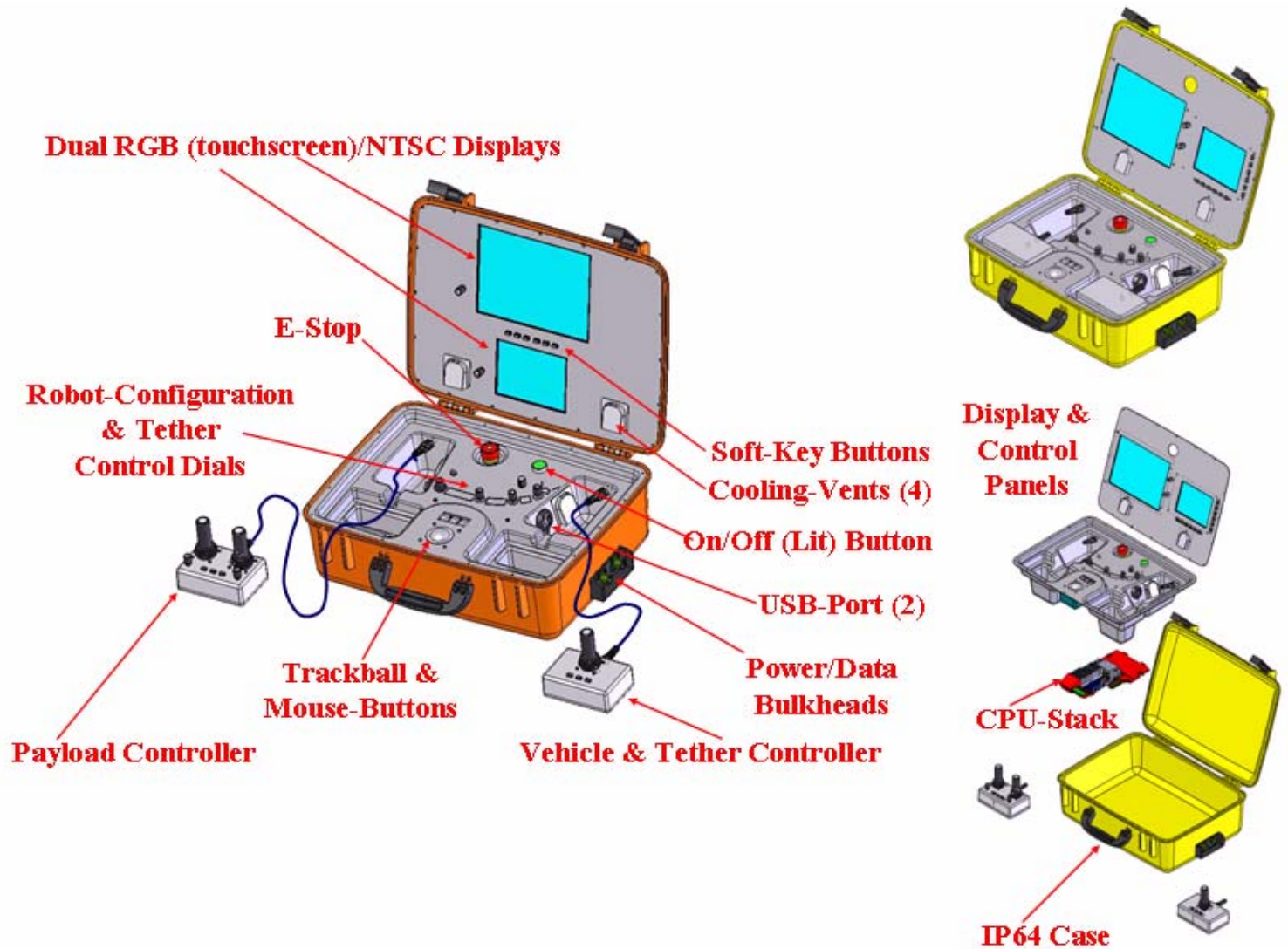

Figure 18 : SPIDAR OCU Configuration options

\section{Power Converter and Tether-Anchor}

In order to generate the $500 \mathrm{~W}$ power required by the system, while maintaining a high (yet safe) voltage (at the OCU/anchor and the robot), while minimizing current pushed over the tether, the SPIDAR system required the use of an external stand-alone AC/DC converter. Said unit was then also used as the wiring 'junction-box' as well as the termination of the anchor-point ${ }^{5}$ for the tether. The converter/anchor is configured as a hexagonal metal enclosure as a heat-sink for the three (3) AC/DC converters (100 VAC

\footnotetext{
5. the tether itself is anchored by a set of ropes attached to a set of self-tigthening 'chinese-fingers' that clamp onto the outside of the tether where the Kevlar strength-members have been exposed, bent over and molded into a tapered plug on the tether.
} 
from the generator to $300 \mathrm{VDC}$ ) to feed the OCU and the robot with power. A set of end-caps with a fan provide for forced convective cooling across an intake/exhaust to allow operation in $120^{\circ} \mathrm{F}$ ambient air and direct sunlight. An image of the assembled and exploded-view power-converter/anchor is depicted in Figure 19.

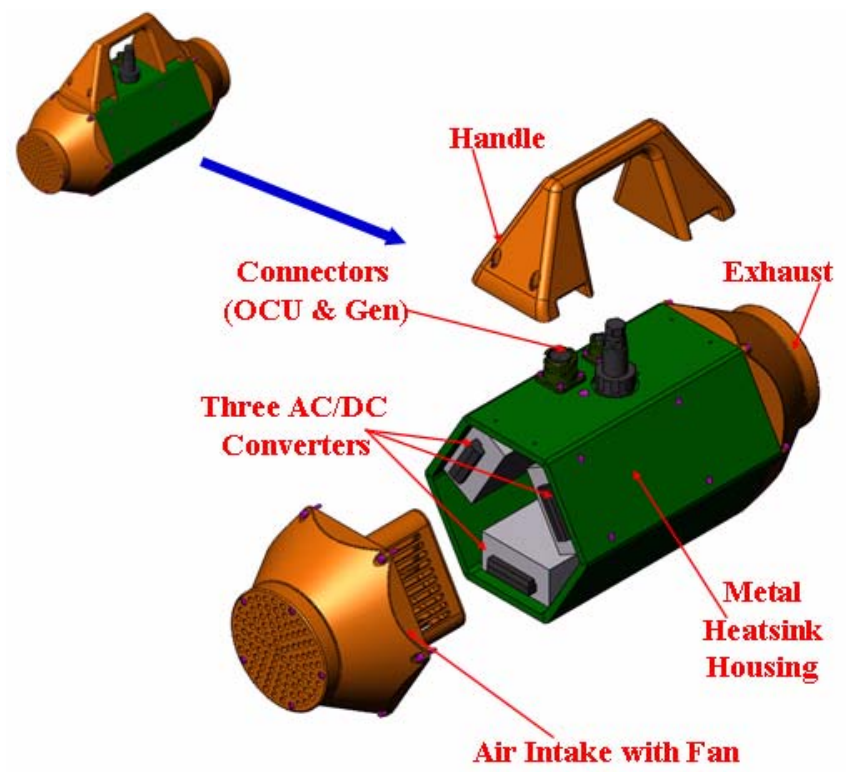

Figure 19 : Assembled and exploded view of the SPIDAR AC/DC Converter unit and anchor-interface

\section{Deployment and Operations}

The SPIDAR system, including the vehicle platform, the AC generator and converter/anchor, as well as the small light-weight OCU, are designed to be deployed (carried on-site) by a single operator, as depicted in Figure $20^{6}$.

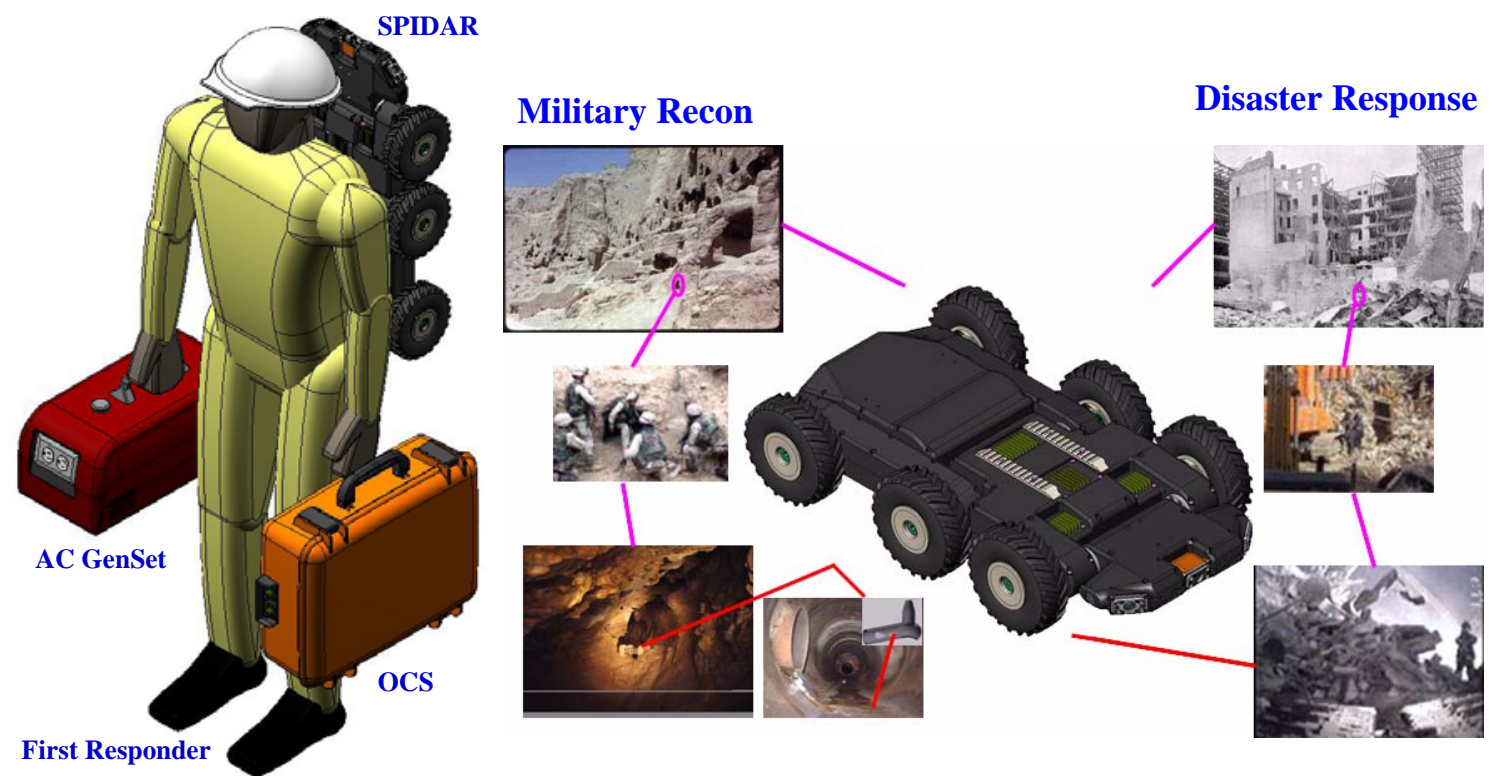

Figure 20 : Deployment of SPIDAR by a single person into multiple civil-defense/military missions

6. Note that the notion is that SPIDAR can be deployed into military as well as civil-defense missions, capable of accessing and inspecting a variety of arenas requiring a rappelling robot system (see Figure 20). 


\section{TESTING}

\section{Tether Management System Testing}

The TMS was pre-prototyped in order to validate key performance and behavior requirements for both active as well as passive performance and fail-safe features (see Section titled Tether Management System (TMS) on page 10) - a picture of the TMS is shown in Figure 21. Tests that included (i) electronic noise quantification (impact of power-conductors on digital data-carriers in the tether) as well as (ii) sharp-bend cable-ruggedness under load, were carried out and led to the specification of the final tether used in the current prototype design. Test conditions (see Figure 22) under full electrical and mechanical load showed the tether design to be viable for the SPIDAR applications being envisioned.

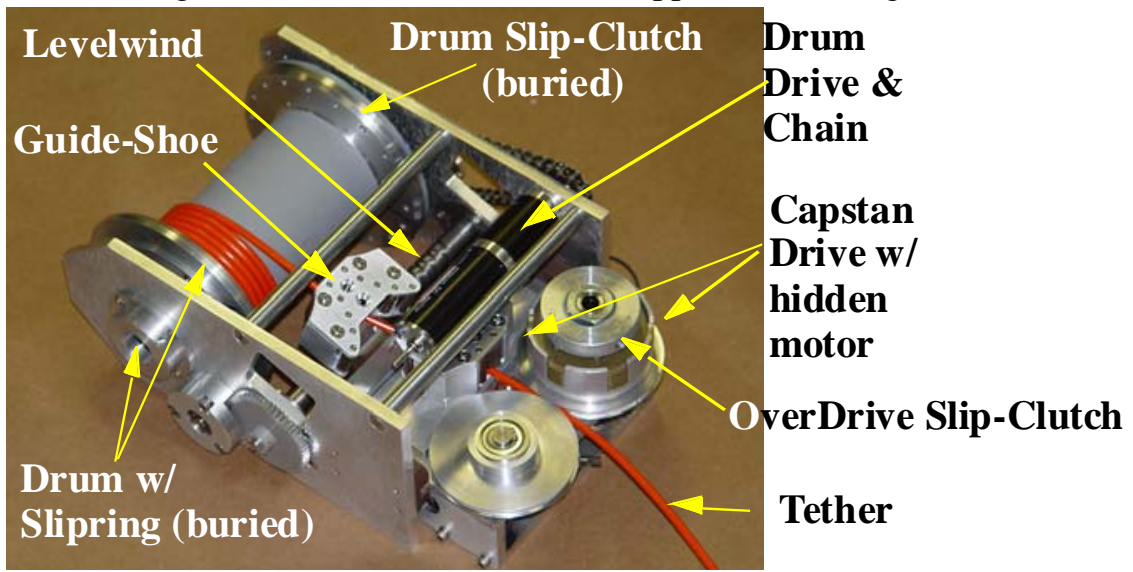

Figure 21 : TMS pre prototype system assembly withe detailed call-outs of subsystem elements
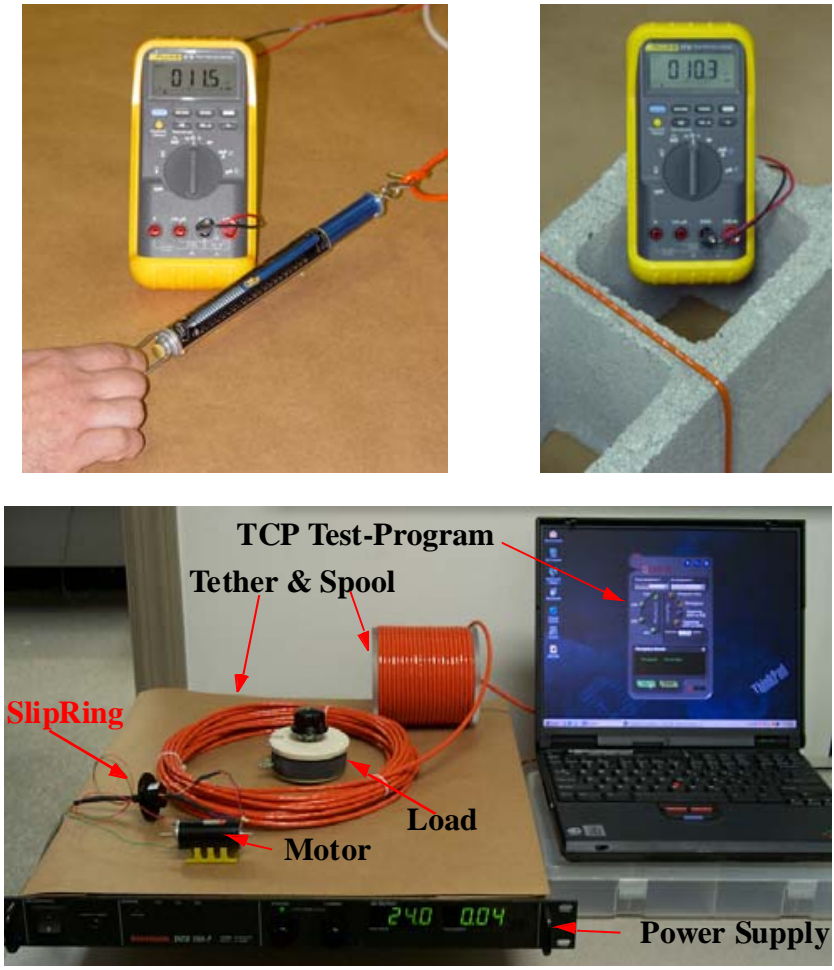

Figure 22 : TMS test-condition example based on resistivity and data-throughput under tension, extreme bending and electrical motor-noise and slipring motions 


\section{Integrated System Functional Testing}

The complete system prototype, consisting of the vehicle, anchor, OCU and power-generator was used for the functional system checkout - see Figure 23. The ability to configure the chassis and sensor-head and the ability to control the locomotion and tethering jointly, was proven out in the laboratory.

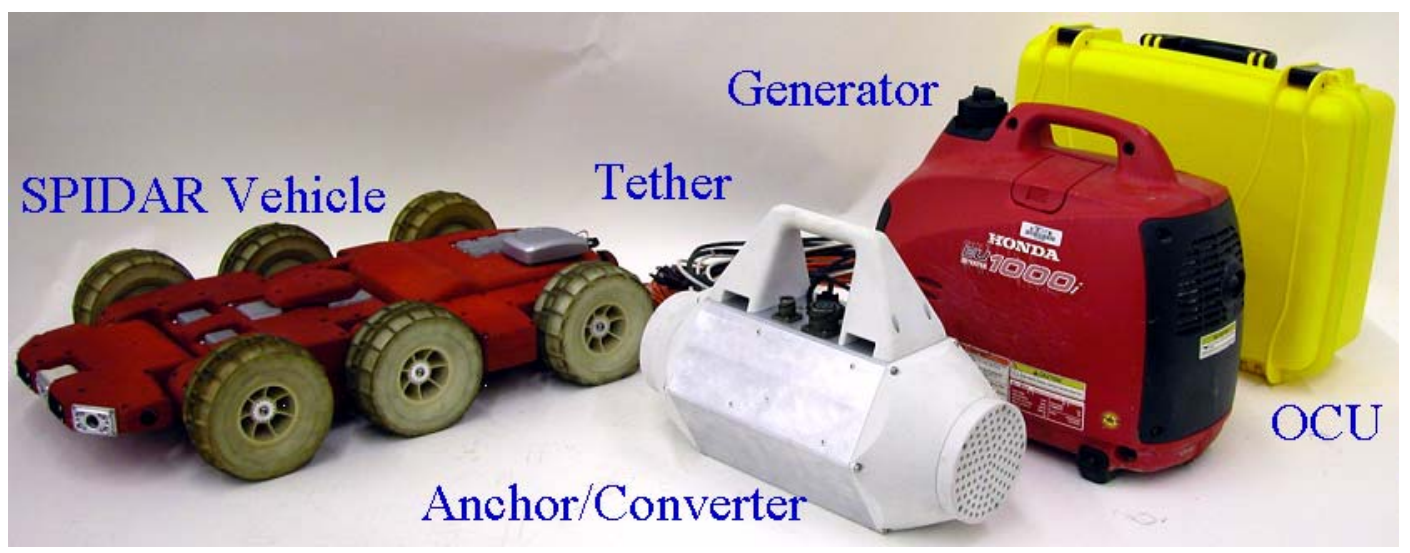

Figure 23 : Prototype SPIDAR system including vehicle, anchor, OCU and generator

\section{TILT-CAM ERA}
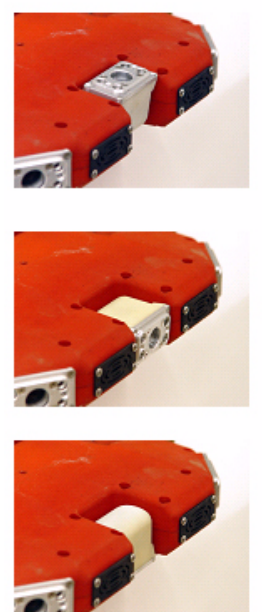

SENSOR-HEAD

UP

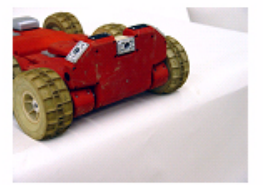

CENTER

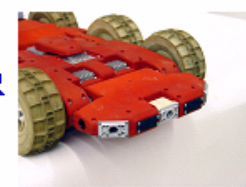

DOWN

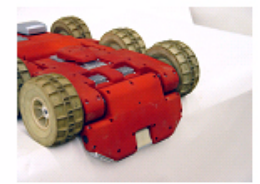

CHASSIS / ABDOMEN
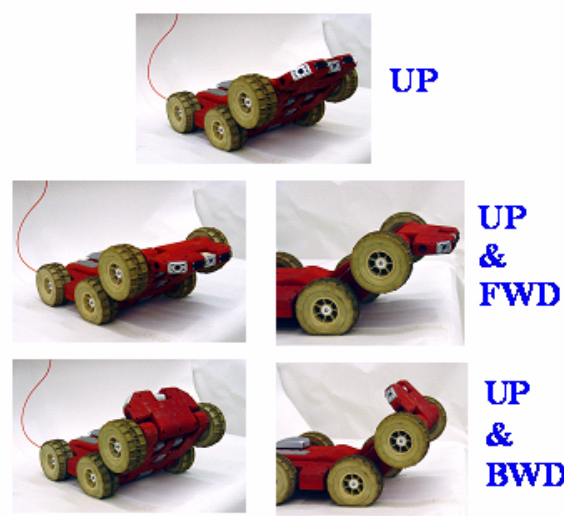

DOWN

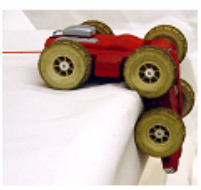

Figure 24 : Vehicle Posturing and articulation capability evaluation

The design capability to adapt different locomotors to the drive-shafts of the vehicle was also implemented and tested. the different configurations for wheeled, half-track (rear-track with front wheels) as well as elliptical and club-feet frontal climbing 'legs' was evaluated. Functionally the system was well suited to the concept of locomotor modularity, with interesting test results and counterintuitive conclusions drawn from field-test evaluations of these configurations - details are provided in the next section. Figure 25 depicts the different locomotion elements and their differing configurations for the vehicle platform. 


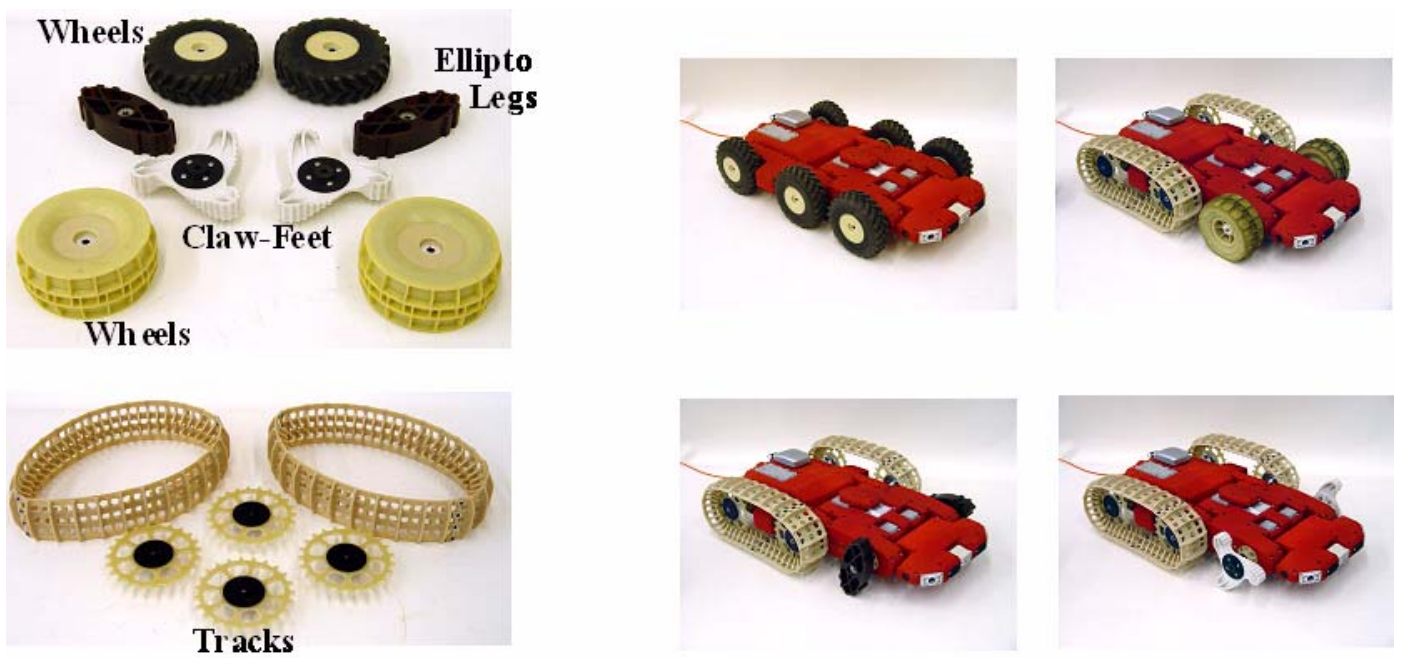

Figure 25 : Varied locomotion configurations

The controller-side of the system, including the OCU, anchor, tether and stress-relief and generator elements were built and used for all indoor/outdoor and field-testing - they are depicted in Figure 26.

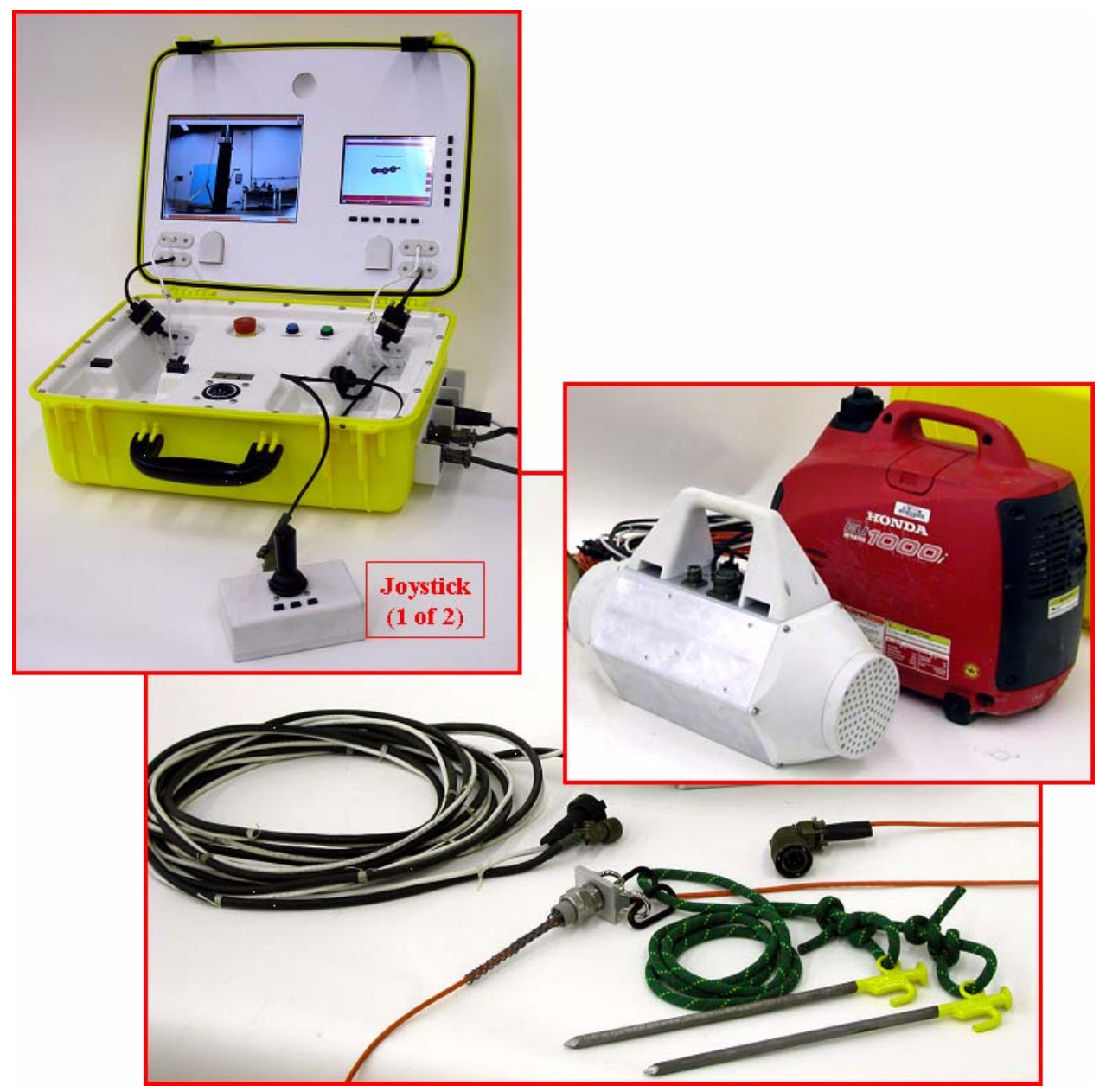

Figure 26 : Operator-side system elements: tether (\& strain-relief), anchor, OCU and generator 


\section{FIELD EXPERIMENTATION}

The testing and evaluation of the system was carried out in the laboratory (functional) as well as at a disaster-team training facility's training rubble-pile. Both of these test-activities are reported on below in a combined fashion, in a more mostly qualitative fashion.

\section{Deployment Site \& Configuration}

Testing was carried out at the Allegheny Fire and Disaster Response training Facility near Pittsburgh (see Figure 27). The testing was carried out using a single 'S\&R operator' carrying the complete load from a staging site to a presumed disaster site, in order to simulate the complete operational scenario (see Figure 27).
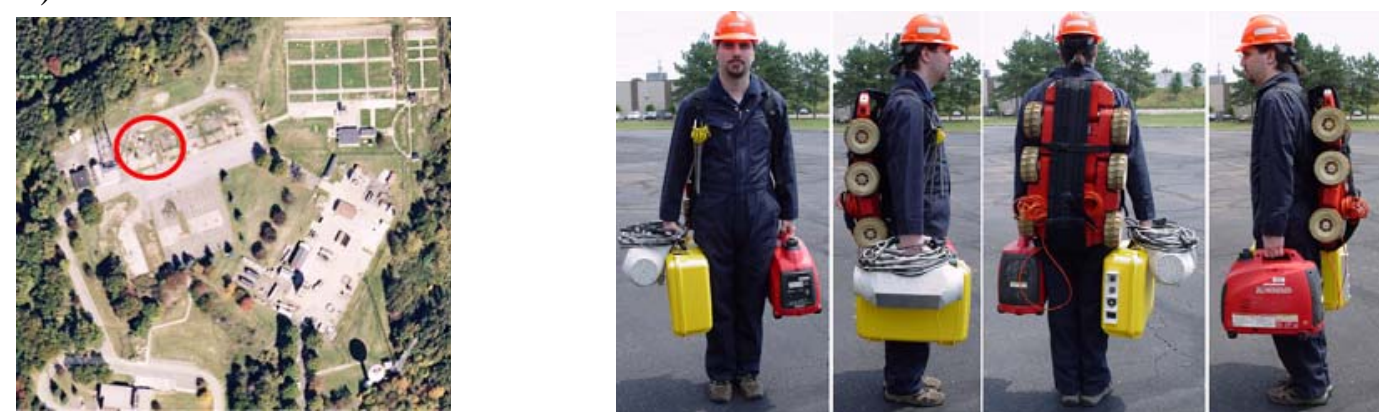

Figure 27 : Field-trial deployment site and single-operator load-out configuration

\section{Field-Testing}

During field-testing the system proved its capabilities (see Figure 28) and showed the value of chassisarticulation, rappelling, multi-sensor telepresence and simplicity of OCU use and unlimited endurance.
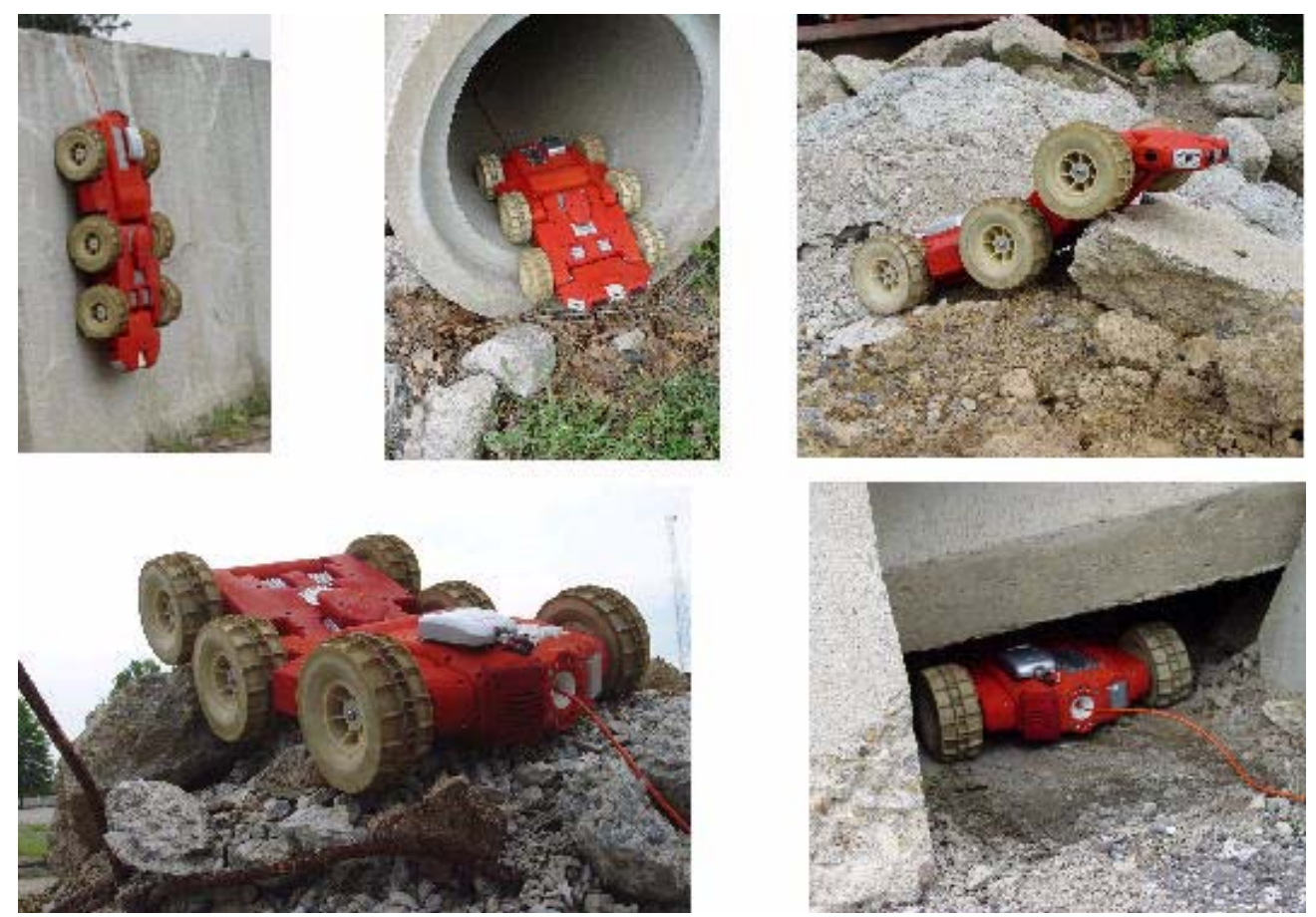

Figure 28 : System experimentation scenarios 


\section{- Overall Driving \& Tethering}

The robot platform was driven both indoors and outdoors over smooth and rough rubble-piles. The primary locomotor configuration that was used was tracked and wheeled. Performance was deemed to be perfectly acceptable and the seemingly slow speed in open terrains, was deemed perfectly adequate in cluttered and confined environments, where progress is slower and executed with more care and purpose.

Typical imagery of indoor and outdoor driving scenarios is depicted in Figure 29.
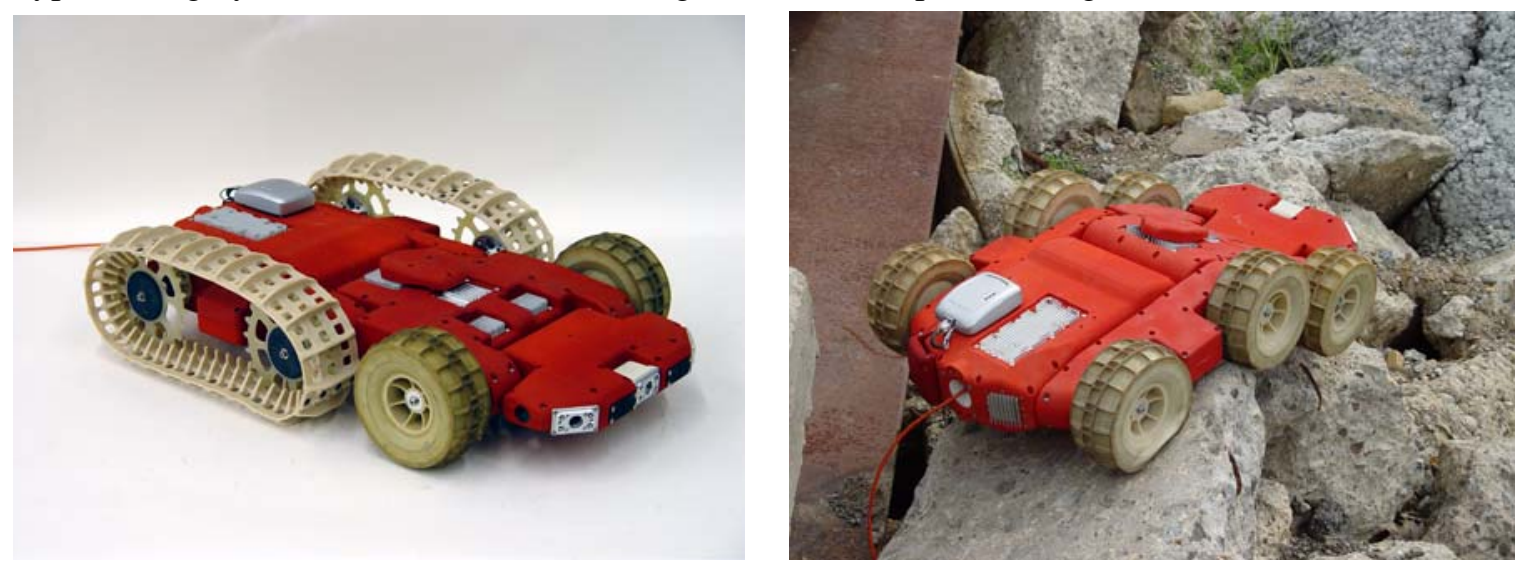

Figure 29 : SPIDAR driving/tethering experimentation both indoors and outdoors on a rubble pile

The combined driving and tether pay-out/-in worked very well, especially given the control laws and noslack parameters that were implemented. Free-fall drops and slip-clutch overrides were also tested and shown to provide sufficient safeguard for the system in case of a free-fall

\section{- Obstacle-Climbing using Posturing}

The robot platform's main articulation features, namely chassis- and sensor-head articulation (for peering and proned push-up), were tested both indoors and outdoors. It was shown that with minimal operator training, a sequence of posturing and driving commands allowed the vehicle to climb onto and over an obstacle that was easily twice the vehicle's chassis height. A depiction of the vehicle in midclimb onto such obstacles, is shown in Figure 30.
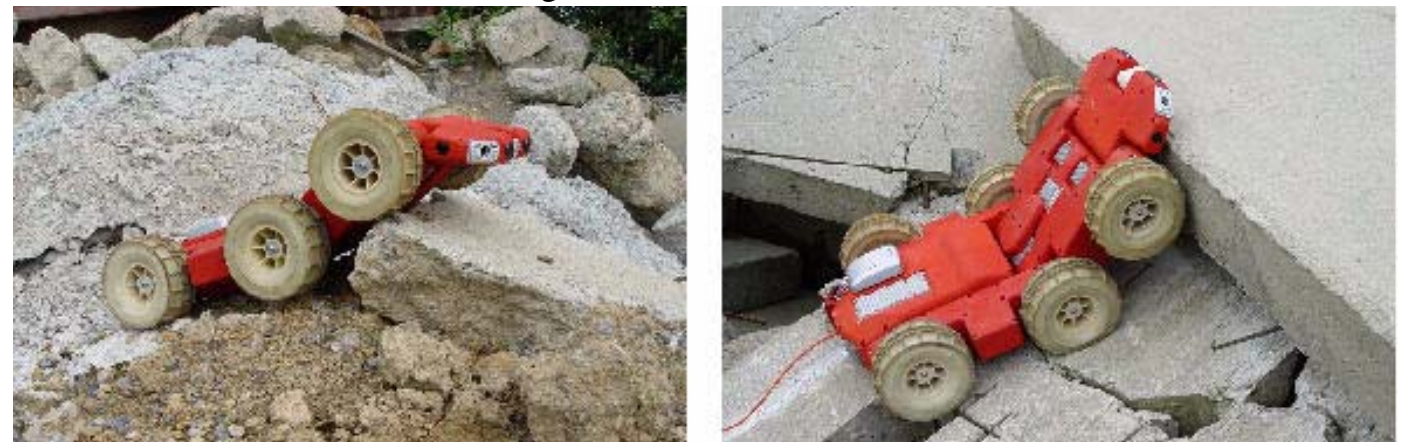

Figure 30 : SPIDAR prototype articulating its chassis/abdomen and sensor head for better inspection and a climbing attempt 


\section{- Locomotor Performance}

Another one of the features that was tested, was the ability of the platform to accept different locomotor options, as depicted earlier in Figure 25. Based on early experimentation, it was determined that neither the claw-feet nor ellipto-legs offered any substantial improvement over a coarse-treaded tire in the front. This is most likely due to the equivalent diameter of these to the wheel and the fact that the rubble pile used for testing was not excessively jagged with relatively even-sized rubble-sections. Furthermore, especially during multi-turn motions on rubble with jagged edges, the tread was found to many times jam and tend to de-tread, leading us to abandon the hybrid tracked configurations from further evaluation. We limited further testing simply to the all-wheel platform (see Figure 31) for consistent data results and evaluation.
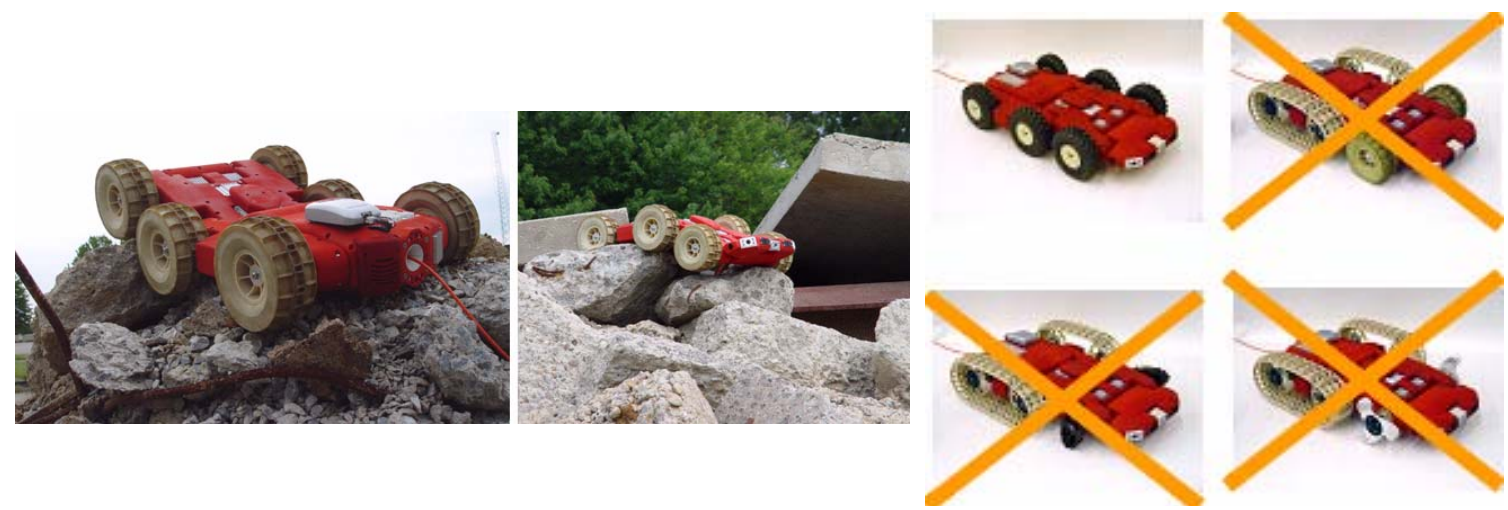

Figure 31 : Multiple locomotor configurations tested; wheeled locomotor deemed most reliable

\section{- Articulation for Inspection}

The articulation of the chassis also allows the tilt-camera and sensor-head to reach spaces, whether above the vehicle or below it (see Figure 32), to perform a more close-up inspection. This is especially valuable for areas that the vehicle will not be able to reach, which will inevitably happen.
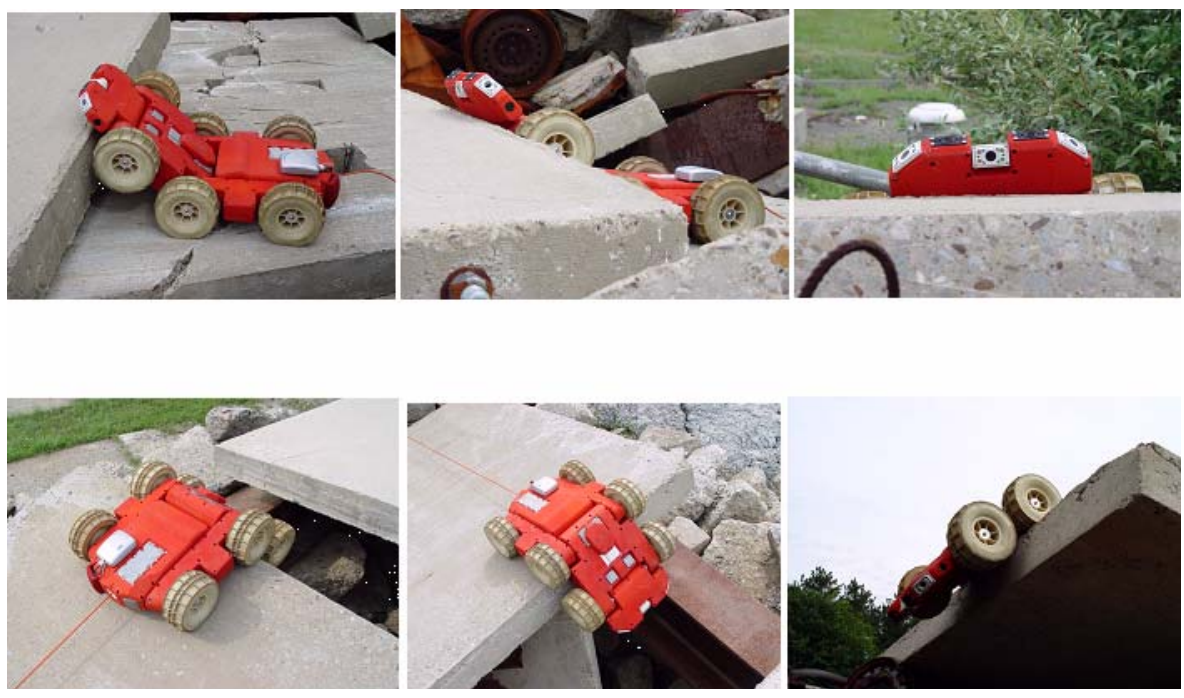

Figure 32 : SPIDAR prototype articulating its chassis/abdomen, sensor head and tilt-camera for (i) better up-above inspection views, and (ii) to perform a crevasse inspection 


\section{- Pipe \& Duct Access \& Inspection}

The robot platform was also tested and shown to be capable of fitting into and driving through severely curved pipe-sections, whether in a rubble-field or municipal sewers (see Figure 33).
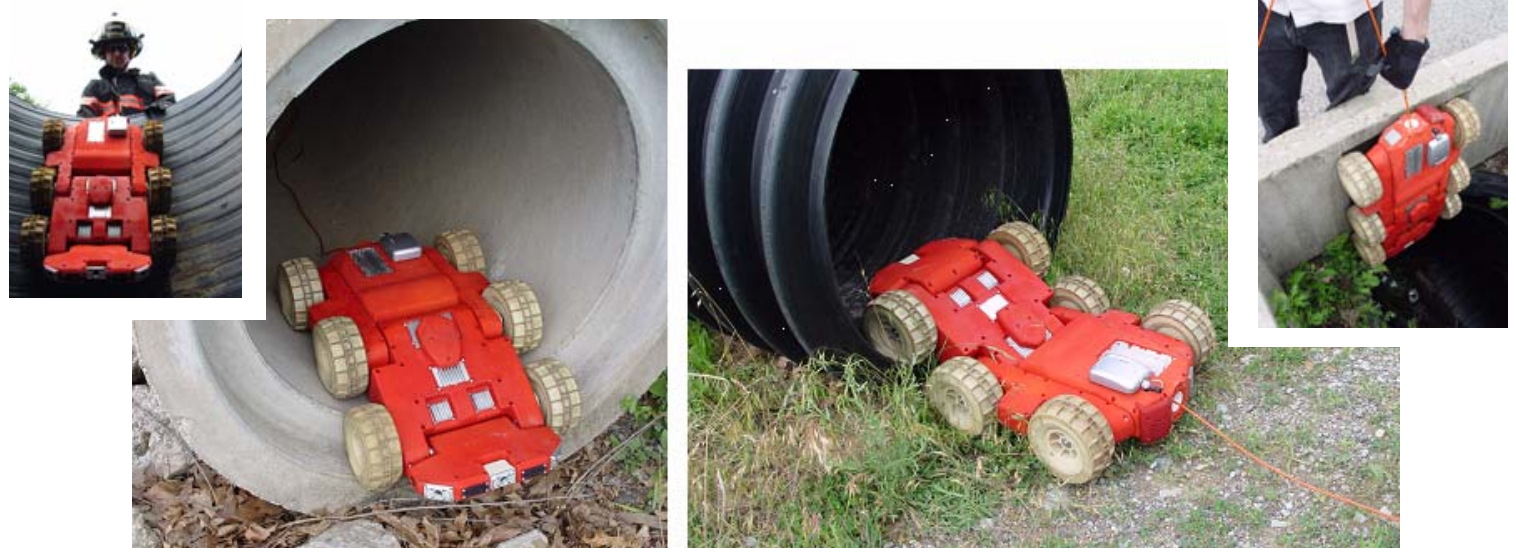

Figure 33 : SPIDAR driving out-of a concrete sewer-main and into an exposed corrugated drainage pipe

\section{- Confined Spaces self-access}

The platforms key attribute of a slim-profile aspect-ratio, was well demonstrated during system evaluation in collapsed slab-sections. The robot was perfectly capable of slipping below slabs, performing an underneath visual inspection and proceeding into areas where a dummy-victim was placed for training purposes. It is thus clear that use of such a system in these kinds of 'pancake' collapses might provide the most immediate and rapid benefit to S\&R workers in the field. Figure 34 shows example images of the tight-space access, internal imaging and rapid training-victim discovery in spaces inaccessible to humans without heavy lifting equipment (irrespective of the time needed to lift slabs and provide access to EMS personnel).
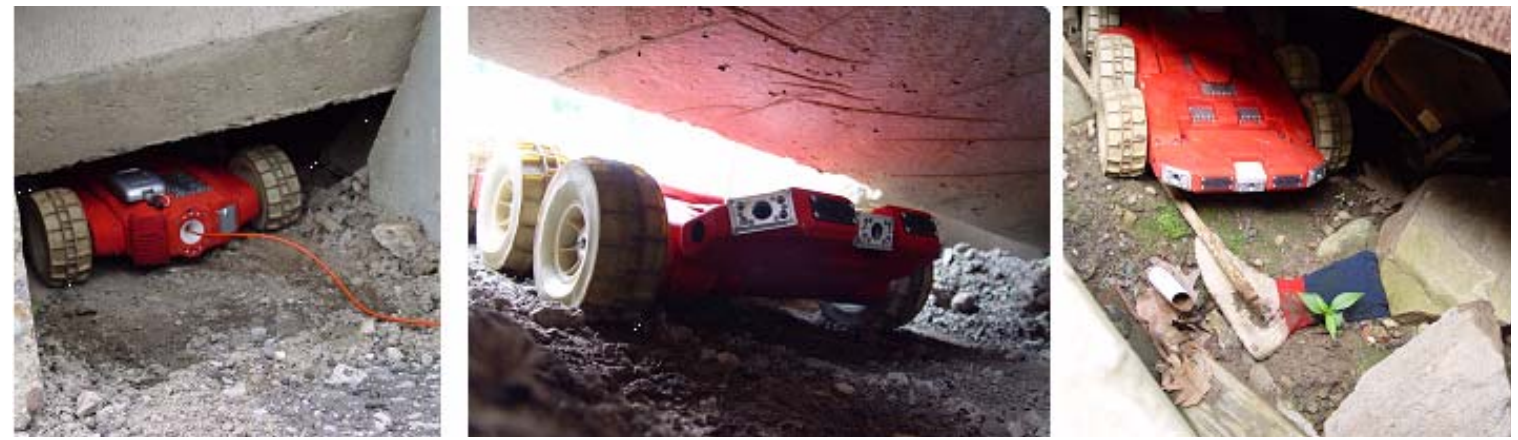

Figure 34 : SPIDAR platform demonstrating extremely constrained space-access, articulation, inspection and search capabilities

\section{- Over-Rubble Driving}

During outdoor rubble-pile testing, the system showed its capability to travel over rubble, with a preferred downhill performance index. This means it was capable of controlled and purposeful travel down into the rubble pile, but was not as terrainable climbing back out, unless aided by tether pull-up 
(in reverse) - a not-so-surprising finding. We believe this to also be insensitive to the kinds of locomotors (types and sizes) that were prototyped for evaluation purposes. Chassis/Body articulation was shown to ease and overcome hang-ups and high-centering. Scenarios that were tested are depicted in Figure 30.

\section{- Tethered-Rappelling (Active \& Manual) \& Recovery}

.Another one of the main features of the SPIDAR system that was tested, included its ability to drive over an edge and rappel down the face of the edge. Multiple tests were carried out over rounded, freeand faced edges, as well as other surfaces. It was found that the system is perfectly capable of dropping over and down a ledge or free-fall surface, while using its articulation capabilities to handle the verticalto-horizontal (or other angle) transition in the descent phase. A time-motion image collage is shown in Figure 35, showcasing the rappelling sequence.

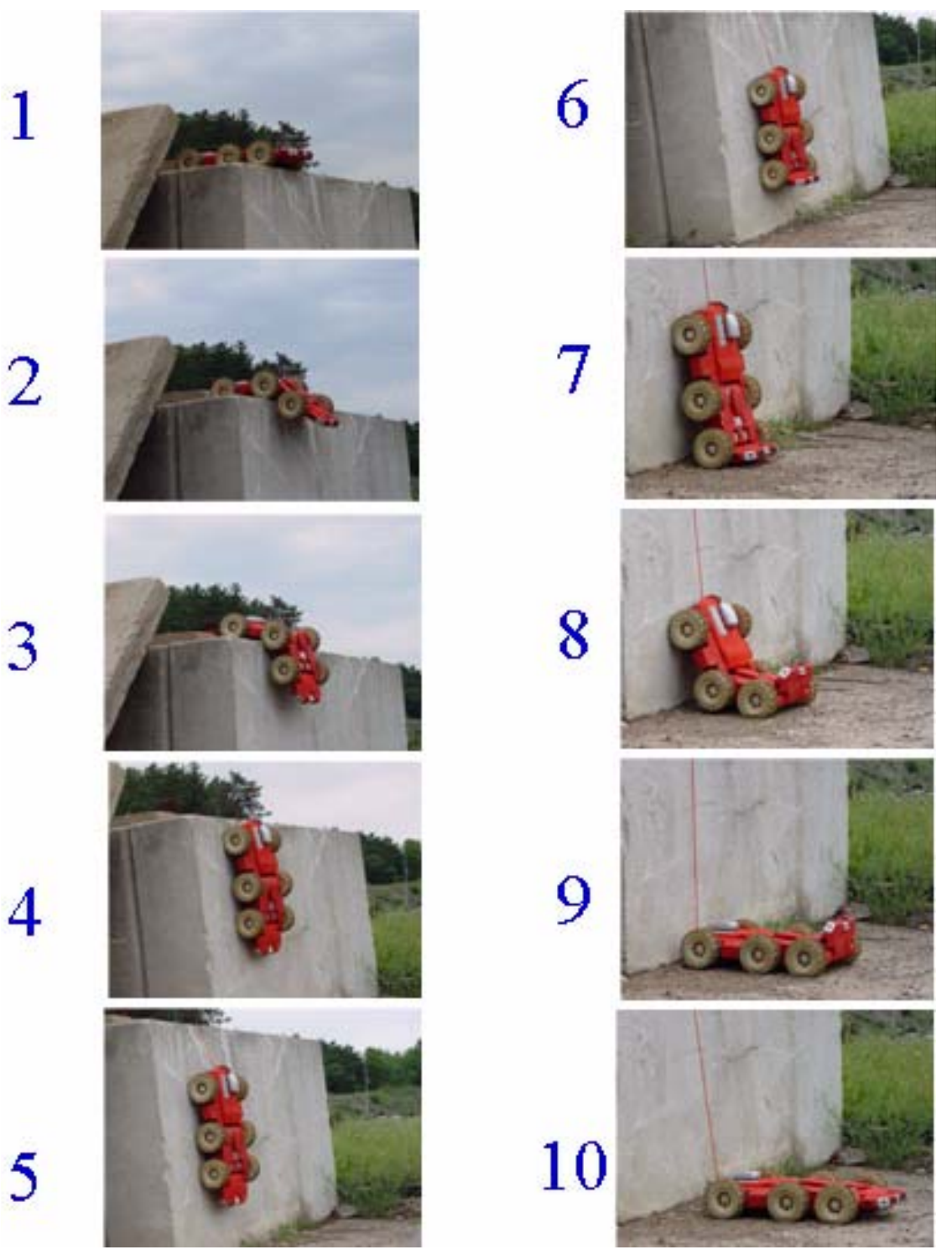

Figure 35 : Time motion picture study of the system’s rappelling capability 
The system was also capable of pulling itself up a sharp-ledged edge, allowing for the full weight of the robot to be carried by the tether and the TMS. We did however only succeed in overcoming the edge of the precipice (in reverse), if the edge was not sharp, but rather curved. The reason for this was the fact that the rear wheels tended to become excessively compressed and not provide a ledge-climb bite on the edge when reversing. A possible solution would be to actually place the leg/claw-feet locomotors on the rear axle for those types of motions, but with an increased leg-length (effective diameter), so they stick out beyond the rear edge of the chassis. This test clearly showed the value and capability of the system in being able to rappel, yet also illustrated the need for additional testing and locomotor design improvement to successfully carry out a rappelling motion in reverse.

\section{SUMMARY \& CONCLUSIONS}

The testing and evaluation of the system was carried out in the laboratory (functional) as well as at a disaster-team training facility's training rubble-pile. The system proved its capabilities and showed the value of chassis-articulation, rappelling, multi-sensor telepresence and simplicity of OCU use and unlimited endurance. Wheeled locomotors were found to be the all-around optimal configuration while sharp-edge backwards rappelling was a substantial challenge. Overall the system performed very well, accessing tight areas and capable of finding (simulated) trapped victims purely by teleoperation and without prior knowledge of the environment. The experimental effort and the conclusions drawn from those results, can best be summarized in bulleted form below:

\section{- Overall Concept \& System Design}

- Tethered rappelling capability designed into the robot adds great capability for S\&R applications, due to the severe terrain such as collapsed urban structures after a natural or man-made disaster. On-board tether-spooling was shown to work very well, and allows for more freedom and dramatic maneuvers regardless of terrain type and distance.

- The controller developed for SPIDAR's TMS clearly proved itself to provide the right and proper operational behaviors during spooling on/off, whether under tension or not and even its safety-features for free-fall protection.

- The articulating chassis proved to be key to terrainability and inspection-access, due to its ability to perch, inch-along (like a seal) and actively change the geometry and thus the CG-location and effects.

- Flexible locomotor running-gear configurations are still believed to be valuable once improved locomotors are developed and tested.

\section{- System Performance}

- Downward/Upward rappelling was shown to work and be robust over and down a sharp ledge and making the transition back on to flat floors, while also being able to rappel back up the same ledge. What the system was not able to do, is rappel backwards over a sharp (especially overhanging) edge (see Recommendations section), while smoother ledges were not a problem.

- Multi-camera viewing key was deemed key for telepresent operations in unstructured environments. Individual camera-switching or multi-camera 
single-view digitally-stitched imagery, was deemed to be key to generate a sense of the environment with the operator. Single-camera or front/rear camera solutions are not necessarily sufficient in very cluttered and unstructured environments.

- Sensor articulation was extremely useful to provide for easier over-precipice and into-crevasse inspections without requiring much vehicle motions and articulation. This was deemed beneficial when approaching rough terrain and inspecting for potential dangers, human presence or other elements of interest.

- The flexible OCU setup (joysticks, etc.) was very useful in the field, by allowing the operator to remove and use the joystick in an operator-selected ergonomic posture, rather than requiring them to hunch over the suitcase OCU, to reach the joysticks and shield the screen for better viewing.

- The 6x6 AWD wheels-only platform proved itself to be the most versatile and robust in rubble-pile inspections. Tracks were simply too prone to detracking, while the club-feet and ellipto-legs were not size-appropriate and will need another design-iteration and re-testing.

\section{- Value as a S\&R and Inspection Platform}

- The tethered rappelling robot adds great capability to the S\&R operator's toolkit. These kinds of platforms offer new capabilities over other existing platforms, whether tethered or untethered, for use in extreme rubble-pile terrains when access, speed of response and survivor-searches are the paramount mission parameter and goal.

- Single operator portability is key to user acceptance based on preliminary feedback from first responders. The ability for a single operator to not only operate SPIDAR, but to also deal with all the logistics of transportation and setup of the system, was a key design driver to enhance its utility and acceptance by existing S\&R technicians.

- Unlimited endurance due to power-tethering is clearly essential to successful S\&R deployments. The goal of tethering a robot to achieve guaranteed communications link and unlimited endurance was also proven out through the design and the experimentation under field-conditions (time, environment, weather, temperature, etc.).

Overall ATK believes that SPIDAR represents a novel and extremely capable and indispensable tool for S\&R teams carrying out their activities in urban settings (post natural/man-made disasters). as well as a tool for special-purpose missions, whether they be civil-defense or military-mission related.

\section{RECOMMENDATIONS}

Based on the results of the experimental evaluation program, the SPIDAR program has collected a number of incremental and drastic improvement recommendations for consideration in future developments of rappelling robots. The items provided below are limited to drastic improvements for future developments for items that did not perform as well as expected (highlighting the negatives rather than the positives for the sake of drastic improvements.

Rappelling back over sharp $\left(\sim 65^{\circ}+\right)$ edges will require a more careful consideration of body articulation, 
traction and tethering articulation. Challenges to be met are highlighted by the type of wall-crawlers developed recently [12], where traction and articulation are key to overcoming a sharp edge during an ascent. Locomotor types require additional research to ensure full advantage is taken to utilize tracks in rough terrain (without detracking) and claw-feet are better utilized for additional traction and edgeclimbing. Lastly, the advantages of a separately articulating sensor-mast, rather than a sensor-studded chassis-element would provide additional separation between the locomotion platform and the telepresence sensing, simplifying the operator's already complex task load.

Earlier designs and preliminary testing data, as well as a performance video were presented late in 2008 [13], with a detailed set of conclusions and recommendation from this program available as soon as the submitted final report [14] is publicly released.

\section{PROJECT STATUS}

The project has completed its Phase II prototype development and testing effort under funding from DARPA to Automatika, Inc. (ATK), including testing in simulated and training environments in the summer of 2008. The final prototype is expected to be demonstrated to the sponsors and first responders in early winter 2008, and undergo additional end-user testing in the USA by the winter of the same year. ATK expects to improve on the system and offer a commercial SPIDAR version sometime in the second half of 2009.

\section{ACKNOWLEDGMENTS}

The authors wish to acknowledge funding support for this effort by the Defense Advanced Research Projects Agency (DARPA) under SBIR Phase I and II grant No. W31P4Q-06-C-0019 through the US Department of the Army.

\section{REFERENCES}

[1] Gage, A., Murphy, R., and Minten, B., "Shadowbowl 2003: Lessons Learned from a Reachback Exercise with Rescue Robots," IEEE Robotics and Automation Magazine

[2] Murphy, R.R., "Rescue Robots at the World Trade Center from Sept. 11-21, 2001“, IEEE Robotics and Automation Magazine.

[3] R. Hogg, NASA Jet Propulsion Laboratory, Micro-Robot Explorer.

[4] Murphy, R., "Rescue Robotics for Homeland Security," Communications of the ACM, special issue on Homeland Security, vol. 27, no. 3, March 2004, pp. 66-69.

[5] Schempf, H. et al, "Less is More: AURORA - an example of minimalistic design for tracked locomotion”, ISSR 2001, Lorne, Australia, November 2001

[6] Murphy, R.R., "NSF Summer Field Institute for Rescue Robots for Research and Response (R4)," AI Magazine, Vol. 25, No. 1, Spring 2004. 
[7] P. Pirjanian, C. Leger, E. Mumm, B. Kennedy, M. Garrett, H. Aghazarian, S. Farritor, and P. Schenker, "Distributed Control for a Modular, Reconfigurable Cliff Robot," Proceedings of the 2002 IEEE, International Conference on Robotics \& Automation (ICRA), Washington, DC, May 2002

[8] Micire, M., "Analysis of the Robotic-Assisted Search and Rescue Response to the World Trade Center Disaster,” Masters Thesis, University of South Florida, July 2002.

[9] Schempf, H. et al, “Evolution of Urban Robotic Systems Developments”, IEEE/ASME Int. Conference on Advanced Intelligent Mechatronics, September 19-22, Atlanta, GA, 1999

[10] D. Apostolopoulos and J. Bares, "Locomotion configuration of a robust rappelling robot," Proceedings of the 1995 IEEE/RSJ International Conference on Intelligent Robots and Systems, Human Robot Interaction and Cooperative Robots (IROS '95), Vol. 3, August, 1995, pp. 280 - 284

[11] Franz Hover, Mark Grosenbaugh and Michael Triantafyllou, "Calculation of Dynamic Tensions and Motions of Towed Underwater Vehicles”, IEEE, Journal of Oceanic Engineering, 1994.

[12] http://www.bostondynamics.com/content/sec.php?section=RiSE

[13] Schempf, H. et al, "SPIDAR: SPinneret for Inspection and Reconnaissance in Search and Rescue Applications”, 2008 IEEE Int. Workshop on Safety, Security and Rescue Robotics, Sendai, Japan, October 21-24, 2008

[14] Schempf, H. et al, "SPIDAR: A SPinneret tethered rappelling search-and-rescue robot for extreme environments”, SBIR II Final Report to DARPA

[15] Jacoff, A., Weiss, B., Messina, E., Evolution of a Performance Metric for Urban Search and Rescue Robots (2003), Proceedings of the 2003 Performance Metrics for Intelligent Systems (PerMIS) Workshop, Gaithersburg, MD, September 16 - 18, 2003 